Manuscript Submitted to Earth and Planetary Science Letters

Submitted: February 28, 2016

Revised: August 15, 2016

\title{
Exploration of Remote Triggering: A Survey of Multiple Fault Structures in Haiti
}

Chastity Aiken ${ }^{1,2 \dagger}$, Kevin Chao ${ }^{3}$, Hector Gonzalez-Huizar ${ }^{4}$, Roby Douilly ${ }^{5}$, Zhigang Peng ${ }^{1}$, Anne Deschamps ${ }^{6}$, Eric Calais ${ }^{7}$, and Jennifer S. Haase ${ }^{8}$

${ }^{1}$ Georgia Institute of Technology, School of Earth and Atmospheric Sciences, Atlanta, GA

${ }^{2}$ University of Texas at Austin, Institute for Geophysics, Austin, TX

${ }^{3}$ Center for Optimization and Statistical Learning, Northwestern Institute on Complex Systems, Northwestern University, Evanston, IL

${ }^{4}$ University of Texas at El Paso, Department of Geological Sciences, El Paso, TX

${ }^{5}$ Purdue University, Department of Earth, Atmospheric, and Planetary Sciences, West Lafayette, IN

${ }^{6}$ Université Nice Sophia Antipolis, Géoazur ,Nice, France

${ }^{7}$ Ecole normale supérieure, Department of Géosciences, PSL Research University, Paris, France

${ }^{8}$ University of California, Institute of Geophysics and Planetary Physics, San Diego, CA

Corresponding Author: Chastity Aiken

Address: University of Texas at Austin, Institute for Geophysics, J.J. Pickle Research Campus, Bldg. 196, 10100 Burnet Rd. (R2200), Austin, TX 78758-4445

Email: caiken@ig.utexas.edu

Phone: 404-997-2536

${ }^{\dagger}$ Now at University of Texas at Austin, Institute for Geophysics 
Abstract. Triggering studies provide an important tool for understanding the fundamental physics of how faults slip and interact, and they also provide clues about the stress states of faults. In this study, we explore how seismic waves from the 27 February 2010 Mw8.8 Maule, Chile mainshock interact with the left lateral strike-slip Enriquillo-Plantain Garden Fault (EPGF) and surrounding reverse faults in the southern Haiti peninsula. The Chile mainshock occurred $6,000 \mathrm{~km}$ away and just 46 days after the 12 January $2010 M w 7.0$ Haiti earthquake, a tragic event which activated multiple faults in the southern Haiti peninsula. During the surface waves of the Chile mainshock, several tectonic tremor signals were observed, originating from south of the EPGF trace. Cross-correlation of the triggered tremor and transient stresses resolved onto to the EPGF indicates that the Love wave of the Chile mainshock was the primary driving mechanism of the triggered deep shear slip and tremor signals, as opposed to dilatational stress changes generated by the Rayleigh wave. We also searched for any influence of transient stresses on Haiti aftershock activity by applying the matched filter technique to multiple days of seismic data around the time of the Chile mainshock. While we identified a slight increase in Haiti aftershock activity rate, the rate changes were significant only when small magnitude events were included in the significance tests. These observations are generally consistent with recent inferences that deep tectonic tremor is more sensitive than shallow earthquakes to external stress perturbations.

\section{Introduction} major plate-boundary faults, at times accompanying geodetically recorded slow-slip events [e.g.,

61 Beroza and Ide, 2011]. Sometimes tremor and earthquakes can be triggered by transient stress

62 changes associated with the passing seismic waves of earthquakes [e.g., Peng and Gomberg,

63 2010; Hill and Prejean, 2015]. This process of fault failure induced by seismic waves is

64 commonly known as 'dynamic triggering' and has been observed worldwide in a wide range of

65 tectonic environments [e.g., Brodsky and Prejean, 2005; Velasco et al., 2008; Peng and

66 Gomberg, 2010; Hill and Prejean, 2015]. Because seismic waves of distant earthquakes are

67 capable of inducing fault failure, triggering studies can be used as a probe to not only understand

68 a fault's current state of stress but to also better understand how seismic activity occurs on active

69 fault systems and how faults interact with one another [Brodsky and van der Elst, 2014]. 
Dynamic triggering generally occurs when transient stresses act in the same direction as a

71 fault's natural motion, i.e. dynamic Coulomb stress increases [Hill, 2012], but dynamic

72 triggering can also occur as a result of secondary stress transfer [e.g., Hill and Prejean, 2015].

73 One example of secondary transfer is movement of fluids that exist in Earth's crust by passing

74 seismic waves [e.g. Brodsky et al., 2003; Brodsky and Prejean, 2005]. Essentially, seismic waves

75 can pressurize fluids in Earth's crust, which may unclamp a fault if great enough and thereby

76 reduces a fault's normal stress and promotes failure, according to the Coulomb failure model

77 [Hill, 2012]. Such a secondary triggering process is thought to be responsible for the observation

78 of dynamically triggered earthquakes in extensional and transtensional regions (geothermal and

79 volcanic regions) with ample fluids [e.g., Prejean et al., 2004; Hill and Prejean, 2015]. High

80 fluid pressure is also thought to be a contributing factor for the dynamic triggering of tectonic

81 tremor in compressional regions (subduction zones) [Peng and Gomberg, 2010; Beroza and Ide,

82 2011] and transpressional regions such as the San Andreas Fault in California [Hill et al., 2013;

83 Peng et al., 2015] and the Oriente Fault in Cuba [Peng et al., 2013], as well as the Queen

84 Charlotte Fault and Eastern Denali Fault in western Canada [Aiken et al., 2013; 2015].

85 In this study, we explore dynamic triggering in the southern Haiti peninsula region

86 (Figure 1). This region experienced a 240-year quiescence of moderate-size and larger

87 earthquakes until 12 January 2010 when a Mw7.0 Haiti earthquake occurred [Bakun et al., 2012].

88 Prior to the 2010 Haiti earthquake, no research quality stations were in operation in the region.

89 The Haiti earthquake prompted many institutions to deploy temporary and permanent seismic

90 stations surrounding the plate-bounding Enriquillo-Plantain Garden Fault (EPGF), both on land

91 and offshore (Figure 1a) to record aftershock activity [e.g., Mercier de Lépinay et al., 2011].

92 Aftershock activity delineated a previously unmapped north-dipping transpressional fault north 
93 of the EPGF as the source of the Haiti earthquake (now known as the Léogâne Fault). Due to

94 static stress transfer, aftershocks also occurred on the reverse Trois Baies Fault (TBF) and

95 transpressional EPGF [Douilly et al., 2013]. It is worth noting that aftershock zones are known to

96 be susceptible to triggering [e.g., Hough el al., 2003; Jiang et al., 2010] due to their critically

97 stressed state attributed to stress changes caused by the mainshock.

(a)

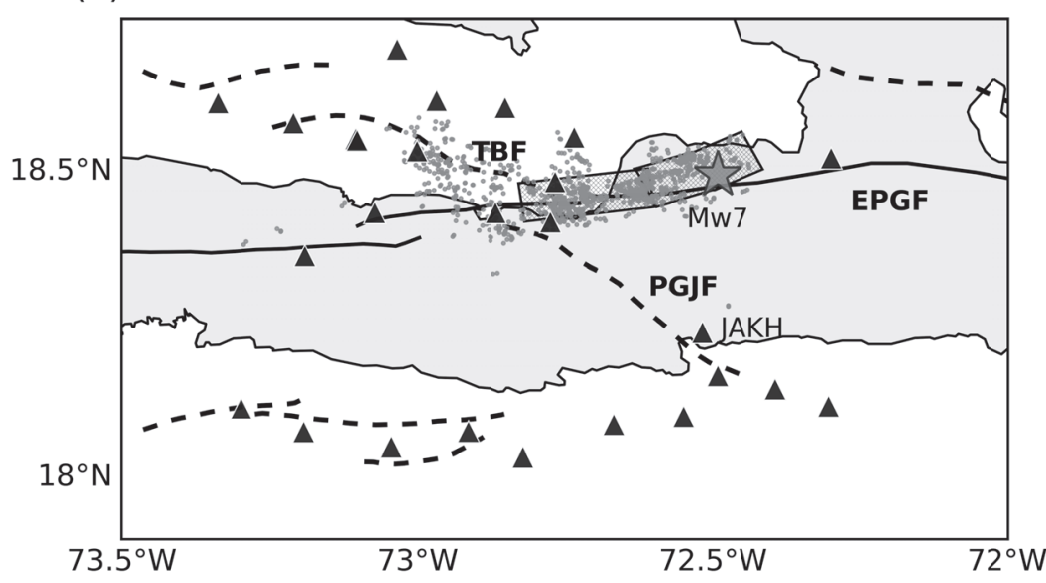

(b)

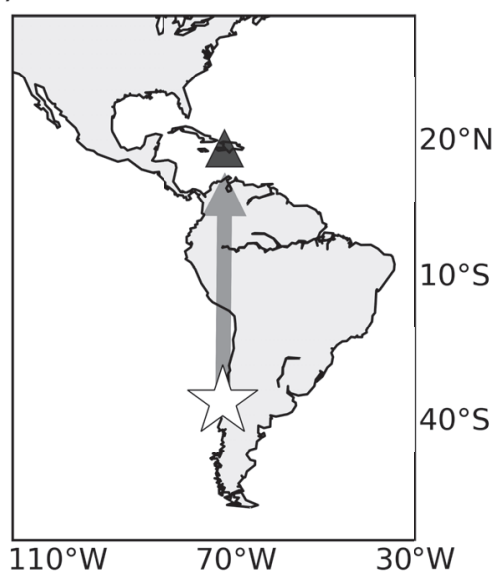

98 (c)

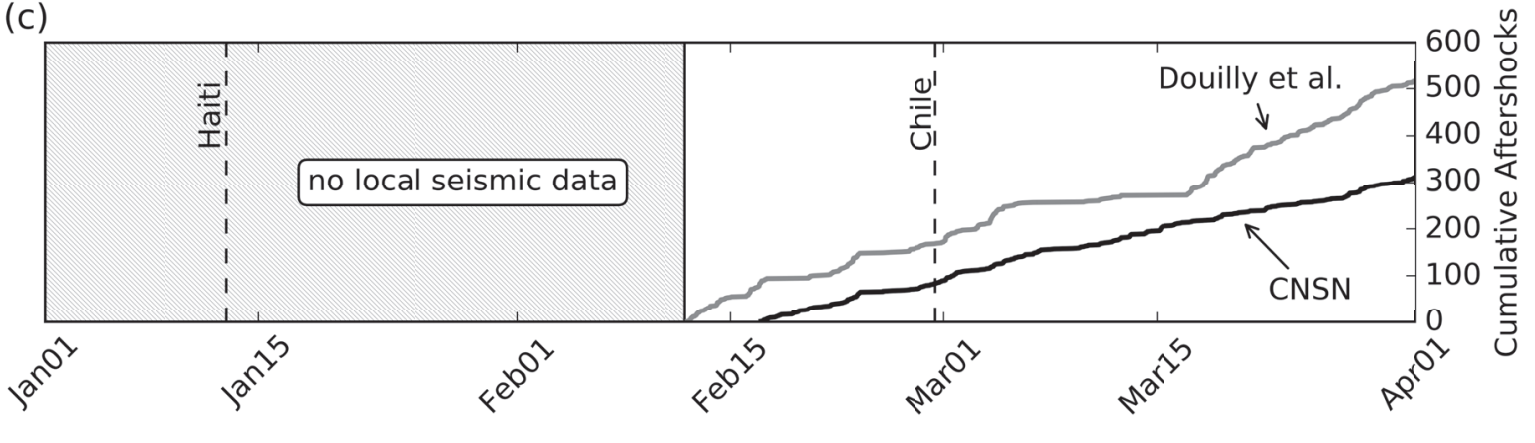

Figure 1. Southern Haiti study region and local seismicity. (a) Left-lateral strike-slip EnriquilloPlantain Garden Fault (EPGF, solid black line) marks the boundary between the Caribbean Plate to the south and Gonâve microplate to the north and is surrounded by several reverse faults (dashed lines), including the Trois Baies Fault (TBF) and Petit Goave-Jacmel Fault (PGJF). Triangles mark seismic stations used in this study. The 12 January $2010 M w 7.0$ Haiti mainshock (gray star) and its aftershocks (gray dots) occur mostly north of the EPGF. Hatched area marks the east and west fault plane of the Léogâne Fault delineated from aftershock locations [Douilly et al., 2013]. (b) Location of the 27 February 2010 Mw8.8 Maule, Chile earthquake (white star) and Haiti region (triangle). Arrow marks seismic wave propagation direction (almost perpendicular to EPGF). (c) Haiti aftershocks from the Canadian National Seismograph Network (CNSN) and Douilly et al. [2013]. Haiti and Chile mainshocks occurred 46 days apart. 
112 earthquake occurred about 6,000 km away from Haiti (Figure 1b). The Chile earthquake is the $6^{\text {th }}$

113 largest earthquake that has occurred since 1900, and its surface waves have triggered

114 microearthquakes and tremor in many regions of the Western Hemisphere [e.g., Fry et al., 2011;

115 Zigone et al., 2012; Peng et al., 2011, 2013; Gomberg and Prejean, 2013; Aiken et al., 2013,

116 2015; Aiken and Peng, 2014], as well as icequakes in Antarctica [Peng et al., 2014]. Because of

117 its widespread triggering and because the southern Haiti region was in a critically stressed state,

118 we investigate here whether the Chile mainshock triggered earthquakes and/or tectonic tremor on

119 faults activated by the Haiti earthquake in the southern Haiti peninsula region. Such an

120 investigation provides an opportunity to better understand how multiple fault structures that are

121 critically stressed respond to external stress perturbations.

\section{2. Search for dynamic triggering of tremor}

\section{$124 \quad 2.1$ General observations}

125 Amidst the ongoing aftershock activity of the Haiti mainshock, we found tremor signals

126 triggered during the Love and Rayleigh (surface) waves of the Chile earthquake (Figure 2),

127 though no similar signals were observed in the few days before the Chile earthquake. Three

128 distinct tremor-like signals containing frequencies of $\sim 1-10 \mathrm{~Hz}$ are clearly visible, coincident

129 with the first few cycles of the Love waves. These tremor signals are easily distinguished from

130 the on-going aftershock activity, since the tremor bursts are emergent signals without distinct $P$ -

131 or $S$-waves (Figure 2b) and have a longer duration compared to small, local aftershocks (Figure

132 2c). Though the tremor signals are visibly different from the local aftershocks, they do look

133 similar to $P$-waves of earthquakes occurring at regional and remote distances. The Advanced 
134 National Seismograph System (ANSS) reported $3 M \geq 5.6$ Chile aftershocks occurring during the

135 time that the Chile mainshock's surface waves arrive in the Haiti region. When predicting the $P$ -

136 wave arrivals of these aftershocks, we found that 2 of the 3 aftershocks do not correlate with any

137 tremor burst arrivals while one aftershock $P$-wave arrival seemingly correlates (Figure 3).

138 However, the $P$-wave amplitude and frequency contents of these aftershocks that seemingly

139 correlate should be lower than that of the Chile mainshock and the tremor (Figure 2).

140 Furthermore, we found that these tremor-like signals propagate in space and time with a shear

141 wave speed of $\sim 3.5 \mathrm{~km} \mathrm{~s}^{-1}$ (Figure S1). These observations are similar to tremor observations at

142 other plate-boundary regions [e.g., Peng and Gomberg, 2010; Chao et al., 2013]. In addition,

143 after speeding up 100 times [Kilb et al., 2012], the tremor signals (Movie S1) are audibly

144 different (start of steam engine) compared to the $P$-wave of the Chile mainshock (distant

145 thunder) and local Haiti aftershocks (firecrackers). 
(a)

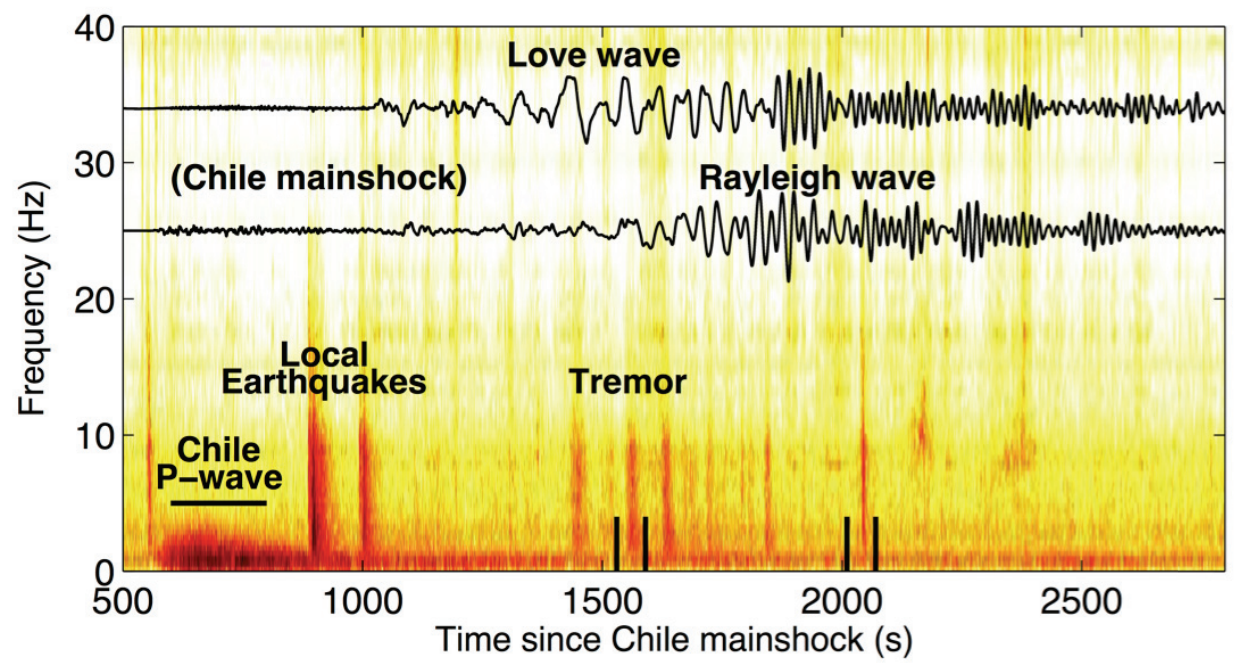

(b)

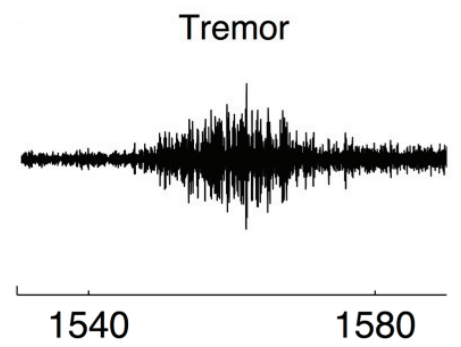

(c)

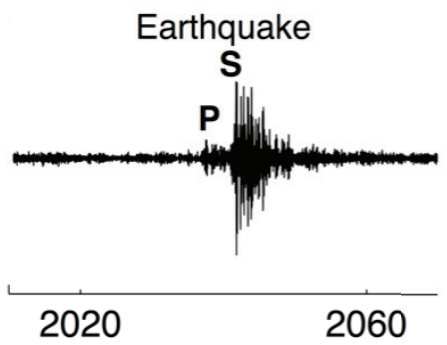

148 Figure 2. (a) Spectra of tremor triggered by the Maule, Chile earthquake and Haiti aftershocks recorded at station JAKH (see Figure 1). There is a strong correlation between the first few cycles of the Love wave and 3 strong tremor bursts. (b-c) Example of a tremor burst that lacks distinct seismic wave arrivals (emergent) and an aftershock having distinct (impulsive) $P$ - and $S$ waves. Times for these events are marked in (a) by vertical black bars.

\subsection{Location of tremor sources}

The 3 tremor signals shown in Figure 2 are observable on all 25 seismic stations ( 6 on

157 land, 19 offshore) in the southern Haiti peninsula after applying a 2-16 Hz band-pass filter

158 (Figure 3, dark arrows). Such a filter enhances local seismic signals and mostly suppresses the

159 teleseismic body wave coda ( $P$ - and $S$-waves) of the remote Chile mainshock and its early

160 aftershocks. In the $2-16 \mathrm{~Hz}$ frequency band, there are a few interspersed tremors between the

161 three strong tremors (white arrows), but they are weaker and hardly visible (if at all) in the 
162 spectrogram (Figure 2). In total, $\sim 10$ tremor bursts appear to be triggered by the surface waves of 163 the Chile mainshock (Figure 3).

164 We located the tremor bursts using an envelope cross-correlation technique [e.g., Chao et 165 al., 2013; Chao and Obara, 2016]. This method searches a 3D grid for the minimum differential 166 times between arrivals on station pairs and theoretical travel times using a local velocity model

167 (Table S1). Prior to locating the tremor, we applied corrections to all stations to account for 168 travel time delays through thick sediments of the ocean basins and other near surface effects, 169 similar to Douilly et al. [2013] (Table S2). 


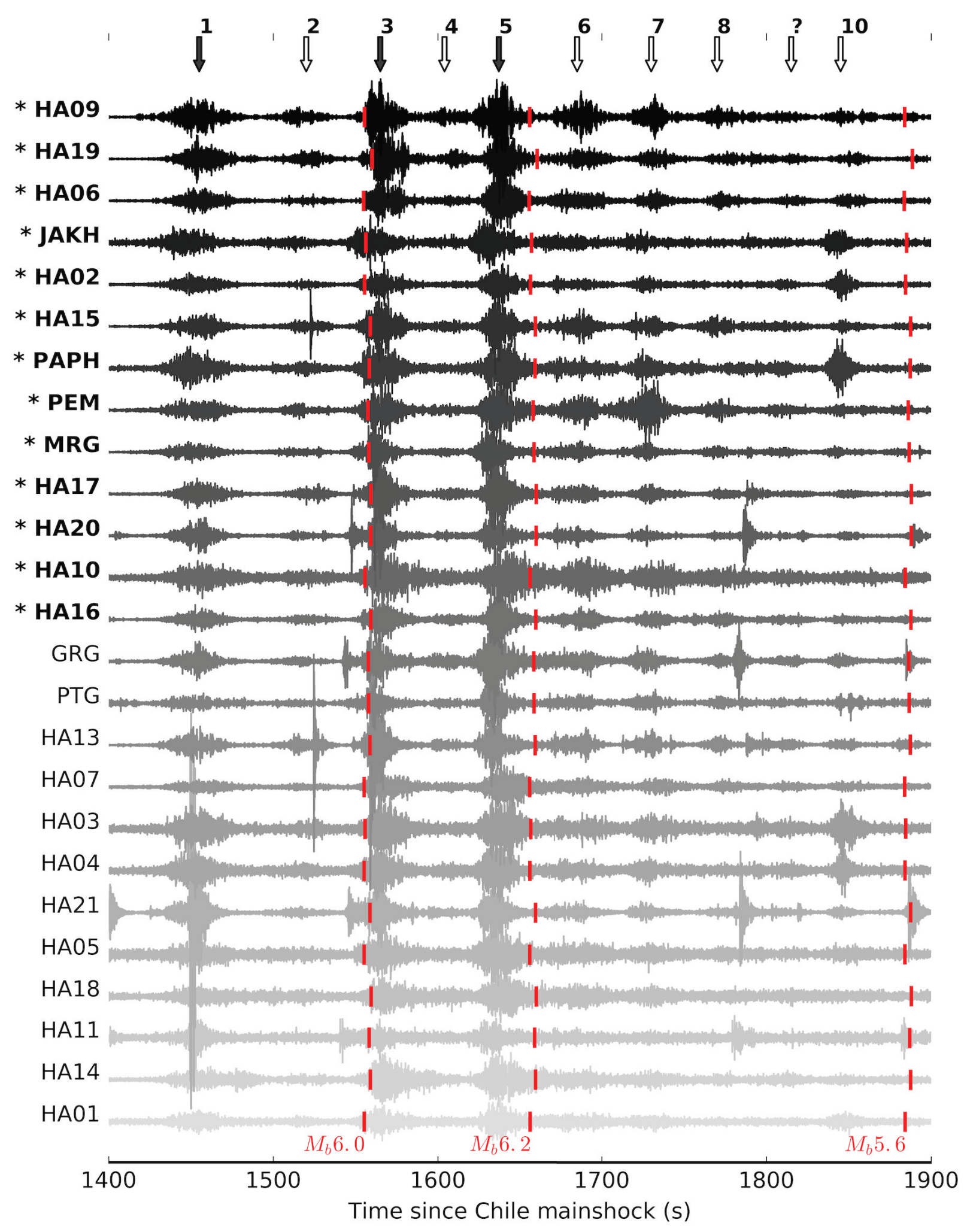

171 Figure 3. Tremor bursts triggered by the surface waves of the Chile mainshock as recorded on 17225 seismic stations ( 6 on land; 19 offshore). Waveforms are filtered to the $2-16 \mathrm{~Hz}$ frequency 173 band. Strong tremor signals (see Figure 2) are marked with dark arrows. Weak tremor signals are 

summarizes the horizontal locations and associated errors for the 9 tremor bursts.

marked by light arrows. Each tremor burst is assigned a number according to its occurrence in time since the Chile mainshock. The $P$-wave arrival times of 3 large aftershocks from the Chile region (predicted using Tau $P$ ) are marked with vertical red lines. We also note their body-wave magnitudes $\left(M_{b}\right)$. Starred station names mark those utilized in the envelope cross-correlation method for tremor source location. Some low magnitude aftershocks with large amplitude, impulsive arrivals are also visible on a few stations.

Because the tremor bursts were not observable on all 25 seismic stations, we computed all possible station combinations using different numbers of stations (10 to 25 ) and finally selected a set of 13 stations that provided a stable location (station names with * in Figure 3). For these 13 stations, we utilized a bootstrapping method such that when one station was dropped, the grid search for the best fitting location was performed. Thus, each tremor burst was located 14 times, once when using all 13 stations and once for each station dropped. Horizontal locations outside one standard deviation $(1 \sigma)$ were rejected, and the final location was computed as the average of the locations within $1 \sigma$ (e.g., Figure S2). We tested this method using 15 stations (Figure S3), but the 13-station set gave smaller horizontal errors and more stable results. When the 13 stations were used to locate the triggered tremor sources, we obtained an average tremor depth of $\sim 25 \mathrm{~km}$ for burst \#5, the largest amplitude tremor triggered by the Chile mainshock (Figures 3 and S2). This depth is similar to previous observations of tremor occurrence on strikeslip faults [e.g., Shelly et al., 2009] and much deeper than that of relocated aftershocks (Figure 4). We were not able to constrain the depths for the other tremor sources, and so we set their depths to be $25 \mathrm{~km}$, similar to that of burst \#5. We note that while most aftershocks occurred north of the EPGF, the 9 locatable tremors originated from south of the EPGF (Figure 4). These locations remain essentially unchanged if we use different sets of stations in the location procedure, such as when 2 stations are added to the location procedure (e.g., Figure S3). Table 1 
(a)

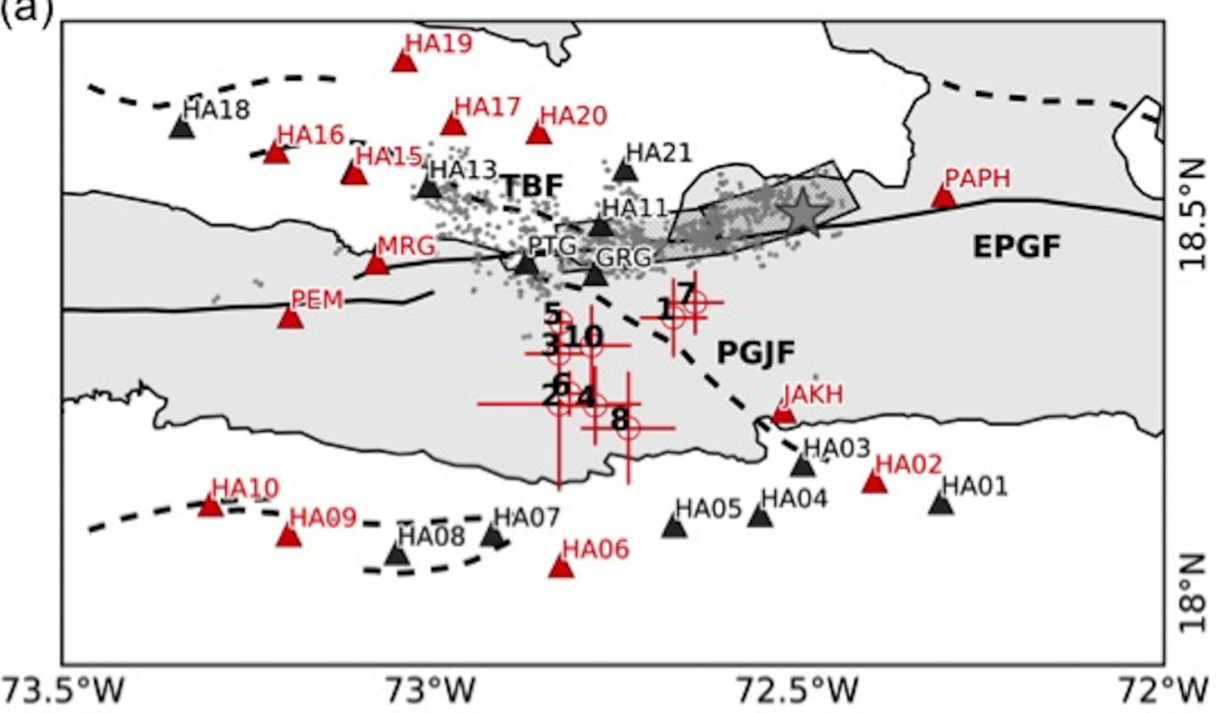

(c)

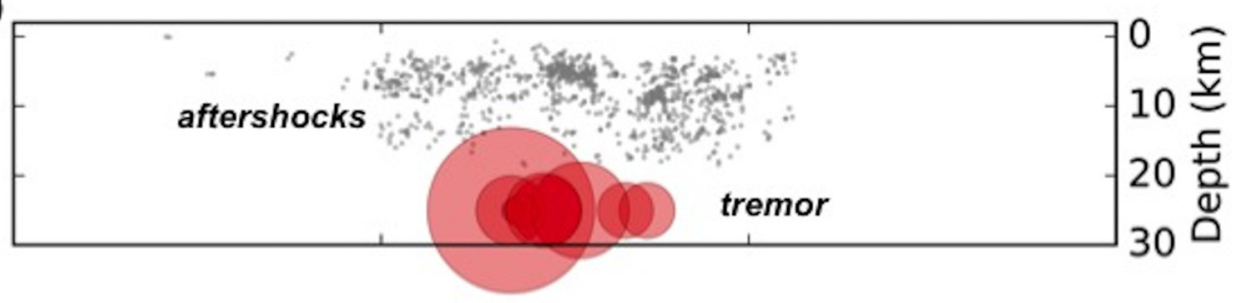

(b)

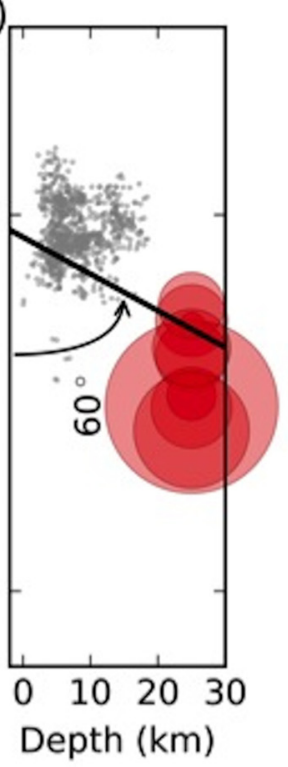

Depth $(\mathrm{km})$

202 Figure 4. (a) Local aftershocks (gray dots) and triggered tremor burst (circles) hypocenters. 203 Crosshairs indicate location errors. Seismic stations used for tremor burst location are shown in red. Tremor bursts are numbered in order of occurrence, as in Figure 3. Other notations and symbols are similar to Figure 1a. (b) Depth profile in the N-S direction with a high-angle EPGF depicted. (c) Depth profile in the E-W direction. Tremor sources mostly originate from south of the EPGF trace with no apparent migration. Table 1 lists tremor locations and errors. Tremor (circles) sources are translucently plotted red in (b) and (c) to show overlapping locations. Tremor symbol size solely reflects latitude and longitude location errors in (b) and (c),

Table 1. Horizontal locations and associated errors for 9 tremor bursts.* 


\begin{tabular}{ccccc} 
Burst No. & Longitude & Error (+/-) & Latitude & Error (+/-) \\
\hline 1 & $-72.6675^{\circ}$ & $0.0442^{\circ}$ & $18.3592^{\circ}$ & $0.0500^{\circ}$ \\
2 & $-72.8233^{\circ}$ & $0.1096^{\circ}$ & $18.2450^{\circ}$ & $0.1133^{\circ}$ \\
3 & $-72.8233^{\circ}$ & $0.0446^{\circ}$ & $18.3117^{\circ}$ & $0.0483^{\circ}$ \\
\hline 4 & $-72.7742^{\circ}$ & $0.0467^{\circ}$ & $18.2433^{\circ}$ & $0.0504^{\circ}$ \\
5 & $-72.8208^{\circ}$ & $0.0127^{\circ}$ & $18.3531^{\circ}$ & $0.0150^{\circ}$ \\
6 & $-72.8092^{\circ}$ & $0.0221^{\circ}$ & $18.2592^{\circ}$ & $0.0279^{\circ}$ \\
\hline 7 & $-72.6383^{\circ}$ & $0.0375^{\circ}$ & $18.3792^{\circ}$ & $0.0408^{\circ}$ \\
8 & $-72.7292^{\circ}$ & $0.0625^{\circ}$ & $18.2133^{\circ}$ & $0.0729^{\circ}$ \\
10 & $-72.7792^{\circ}$ & $0.0521^{\circ}$ & $18.3225^{\circ}$ & $0.0517^{\circ}$ \\
\hline
\end{tabular}

* Errors determined from bootstrapping methods by dropping one station for each grid search run. The depths are set to $25+/-5 \mathrm{~km}$, as constrained by burst \# .

\section{$212 \quad 2.3$ Coulomb triggering potential}

\section{$213 \quad$ 2.3.1 Surface wave stresses}

214 As the surface waves of the Chile mainshock passed through the southern Haiti 215 peninsula, they induced transient stress changes. Here, we modeled how these transient stresses

216 behave at the tremor source on a plane oriented similar to the EPGF. In practice, this model of

217 transient stresses caused by surface waves is defined as the 'triggering potential' of the surface

218 waves [e.g., Hill, 2012]. Triggering potential is a measure of the change in Coulomb failure

219 stress $(\delta C F F$, also known as Coulomb failure function) on a fault plane and is estimated from the 220 change in shear $(\delta \tau)$ and normal $\left(\delta \sigma_{n}\right)$ stresses on a fault plane induced from the passing waves,

221 such that

$$
\delta C F F=\delta \tau+\mu \delta \sigma_{n}
$$

223 where $\mu$ is the coefficient of friction on the fault plane. This model accounts for fault geometry,

224 amplitude and dominant frequency of the passing waves, and location (longitude, latitude, and 
225 depth) of the triggered source. Gonzalez-Huizar and Velasco [2011] provided a full description

226 of how to compute changes in the Coulomb failure function from broadband seismograms, and

227 we briefly summarize the method here.

228 First, waveforms from station JAKH were time-shifted to the average location of the 9

229 tremor burst sources using a local velocity model (Table S1), assuming a tremor source depth of

$23025 \mathrm{~km}$. We measured the triggering wave's amplitude and frequency from consecutive peaks in

231 the displacement seismograms and then computed the dynamic stress tensor for those peak

232 values and interpolated them to obtain time-dependent components of stress tensors. Next, we

233 rotated the time-dependent stress tensor to the orientation of the EPGF (E-W strike $=0^{\circ}$, vertical

$\left.234 \operatorname{dip}=90^{\circ}\right)$. Then, the changes in shear $(\delta \tau)$ and normal $\left(\delta \sigma_{n}\right)$ stress were calculated which are

235 used to estimate, the Coulomb failure stress $\delta C F F$ as defined in equation 1. Based on Thomas et

236 al. [2009] and Houston [2015], we select a coefficient of friction $(\mu)$ of 0.1 for the stress

237 modeling at tremor depths. Modeled stress changes are presented as a function of time in what

238 we define as 'stressgrams' (Figure 5).

239 The total stress change is calculated as the sum of the stress changes caused by the

240 Rayleigh and the Love waves of the Chile mainshock. For the EPGF, stress changes caused by

241 the Love wave of the Chile mainshock are much greater than the stress changes caused by the

242 Rayleigh wave. Therefore, the 'stressgram' of the total stress shows almost no difference from

243 the Love wave 'stressgram' (Figure 5). When the tremor envelope function was cross-correlated

244 with the Love and Rayleigh 'stressgrams' computed at the average tremor burst location, we

245 obtained cross-correlation (CC) values of 0.94 and -0.03 , respectively (Table 2 ). One may also

246 notice the trace of the Petit Goave-Jacmel Fault (PGJF), a south-dipping reverse fault, divides the

247 tremor source locations and could also be a likely faulting source for the triggered tremor (Figure 
248 4). The geometry of the PGJF is not well studied, but it is reasonable to assume that it has a dip 249 similar to the Trois Baies Fault, which has a similar strike to the PGJF but lies north of the 250 EPGF. The Trois Baies Fault is known to have a dip of $45^{\circ}$ based on the relocation of 251 aftershocks [Douilly et al., 2013]. Therefore, for PGJF 'stressgram' calculations we used a strike 252 of $125^{\circ}$ and a dip of $45^{\circ} \mathrm{S}$. Similar to the EPGF, the modeling suggests that Love wave stress 253 changes on the PGJF were much greater than those caused by the Rayleigh wave of the Chile 254 mainshock. Furthermore, given this orientation for the PGJF, the Love and Rayleigh waves of 255 the Chile mainshock have smaller stress changes than those resolved on the EPGF (Figure 5) 256 and, when cross-correlated with the tremor envelope, also have lower CC values of 0.72 and $257-0.01$ for the Love and Rayleigh waves, respectively, at the average tremor source location 258 (Table 2). While the Love wave 'stressgrams' indicate that the tremor could be triggered by the 259 Love wave of the Chile mainshock on either the PGJF or the EPGF (CC $=0.71$ and 0.94 , 260 respectively), the tremor is more likely occurring on the EPGF because the degree of correlation 261 between the average tremor location and the resolved stresses at the average tremor location is 262 higher. In addition, the Love wave applied greater stress on the EPGF ( 10 kPa) compared to the 263 PGJF ( 2 kPa). Hence, tremor was more likely triggered on the EPGF.

264 We note that in this study we did not account for the one-sided nature of the tremor 265 envelope when cross-correlating it with 'stressgrams' that have zero mean. Here, we utilized 266 only the positive stress, which is known to trigger tremor [Hill, 2012]. When the stress is 267 negative, the fault will not slip and only background noise is recorded. Tremor envelopes are 268 also utilized for locating tremor sources, as noted in the previous section. Therefore, we are 269 confident that cross-correlating a one-sided tremor envelope with a zero mean 'stressgram' does 270 not omit information about how the triggering occurred. 
(a)

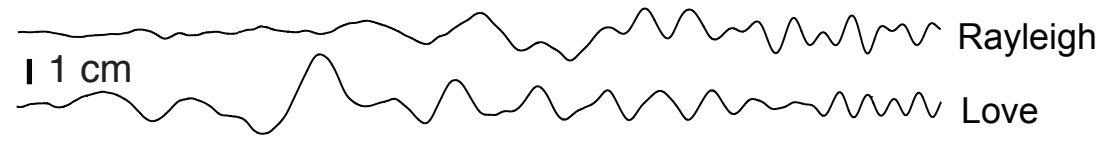

(b)

Enriquillo-Plantian Garden Fault

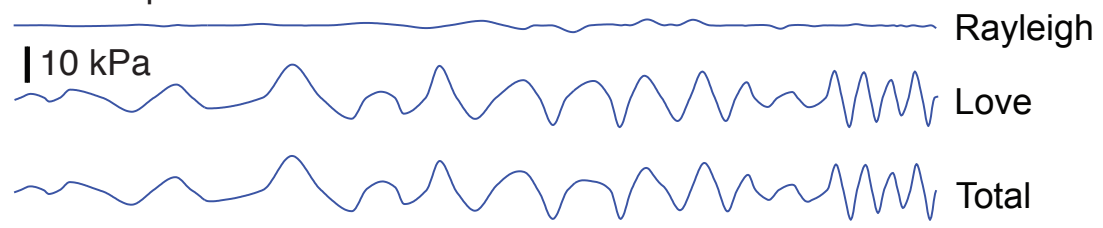

(c)
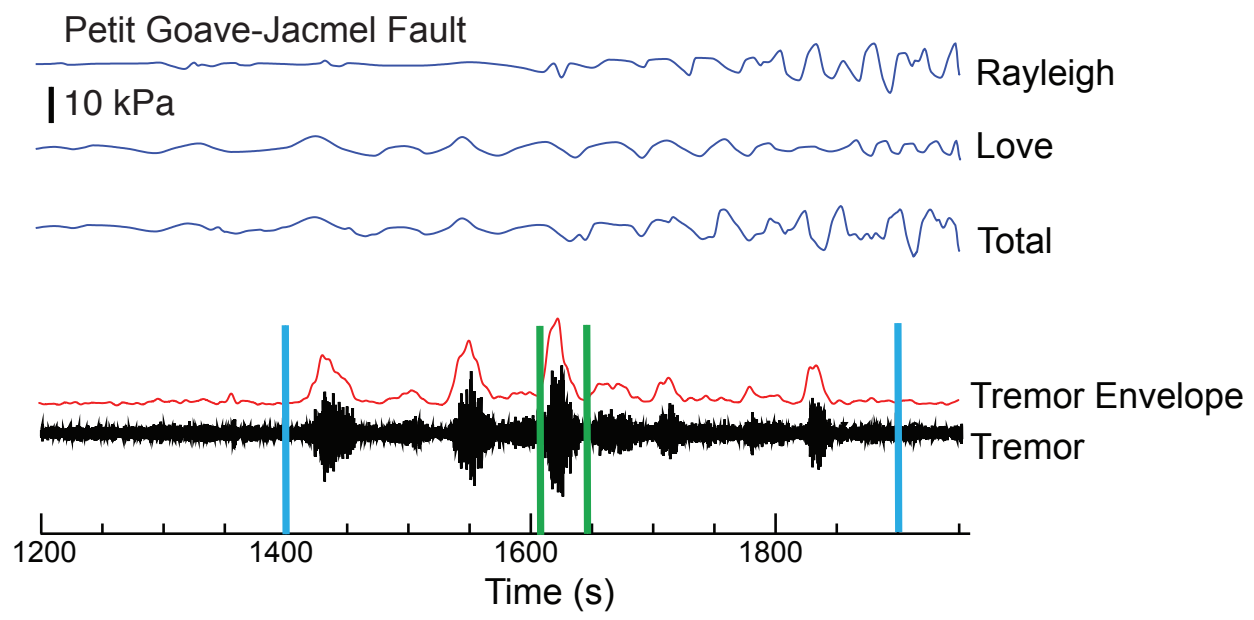

274 Figure 5. Correlations between dynamic stresses of surface waves from the Chile mainshock and tremor activity. (a) Broadband vertical and transverse displacement waveforms from station JAKH. (b) Computed dynamic 'stressgrams' for the surface waves resolved onto the EPGF and PGJF. (c) Band-pass filtered 2-16 Hz waveform showing tremor and its envelope function. Surface wave window (blue bars) and burst \#5 window (green bars) mark the times for crosscorrelation tests indicated in Table 2. 
Table 2. Tremor envelope and 'stressgram' cross-correlation (CC) results.

\begin{tabular}{ccccrr} 
Test & Location of stress & & Surface & \multicolumn{2}{c}{ Normed CC } \\
\cline { 5 - 6 } No. & calculation & CC time (s)* & wave & EPGF & PGJF \\
\hline 1 & 9-burst average & \multirow{2}{*}{1400 to 1900} & Love & 0.94 & 0.71 \\
& & & Rayleigh & -0.07 & -0.01 \\
\hline 2 & burst \# 5 & \multirow{2}{*}{1400 to 1900} & Love & 0.96 & 0.75 \\
& & & Rayleigh & 0.02 & -0.03 \\
\hline 3 & burst \# 5 & \multirow{2}{*}{1610 to 1650} & Love & 0.21 & 0.17 \\
& & & Rayleigh & -0.04 & 0.04 \\
\hline
\end{tabular}

* Time since Chile mainshock

294 how the CC values vary when CC time windows and location of the computed 'stressgram' are 295 changed. Specifically, we tested the variation of the CC value at burst \#5 location (our best 296 location) and time for the EPGF and PGJF (Table 2, tests 2-3). Although changing the size of the 297 time window affects the CC, in all cases the Love wave stresses shows a higher CC than Raleigh

Because not all tremor bursts occur at the average tremor burst location, we also tested wave stresses when resolved onto the EPGF. The high temporal correlation of the tremor bursts with the Love wave for the EPGF suggest that, in this case, the Love wave is responsible for triggering tremor, likely on the deep extension of the EPGF.

In terms of resolving the surface wave triggering potential (equation 1), the coefficient of friction $\mu$ represents the fraction of normal stress changes $\left(\delta \sigma_{n}\right)$ that contributes to dynamic Coulomb stress changes $(\delta C F F)$. The coefficient of friction value $\mu$ used in previous studies is typically around 0.4 for calculations of static Coulomb stress changes [e.g., Toda et al., 2011]. However, it has been shown that $\mu$ at lower crustal depths where tremor occurs can range from 0 to 0.15 [Thomas et al., 2009; Houston, 2015]. In this study, we utilized $\mu=0.1$ for our stress modeling, but we also calculated the surface waves related stress ('stressgrams') using different values of $\mu$ (Tables S4-S5). Regardless the value of $\mu$, the Love wave causes almost no change to the normal stress component $\left(\delta \sigma_{n}\right)$ on a fault plane oriented perpendicularly to the direction of 
310 wave propagation [Gonzalez-Huizar and Velasco, 2011; Hill, 2012]. In addition, the amplitude

311 of the Rayleigh wave was much lower than the amplitude of the Love wave of the Chile

312 mainshock (Figure 5), resulting in a significantly small $\delta \sigma_{n}$ compared with $\delta \tau$. Therefore, given

313 the very low $\delta \sigma_{n}$, we observed no significant change in the modeled $\delta C F F$ ('stressgrams') for

314 different values of $\mu$ for either the EPGF or the PGJF (Tables S4-S5).

315

\subsubsection{Test of fault orientation}

The structures of many faults in the southern Haiti peninsula were not well studied until

318 the $2010 M w 7.0$ Haiti earthquake. No clear evidence of surface ruptures were observed on the

319 EPGF following the Haiti earthquake [Prentice et al., 2010], consistent with other observations

320 that it originated on a north-dipping blind-reverse fault [Calais et al., 2010]. Field observations

321 instead suggested that the EPGF is a vertical to high-angle $\left(>60^{\circ}\right)$ south-dipping structure

322 [Prentice et al., 2010].

323 Given the incidence of the Love wave on the EPGF (Figure 1b), the Coulomb triggering

324 potential predicts triggering solely by the Love wave [Hill, 2012]. In other words, the cross-

325 correlation of the Love wave 'stressgram' and tremor envelope should be close to 1 at some fault

326 dip angle. Hence we can search for the best-fitting dip of the EPGF that gives the highest CC

327 value. To do so, we varied the dip of the EPGF in our triggering potential model between $0^{\circ}$ and

$32890^{\circ}$ and cross-correlated the computed 'stressgram' and tremor envelope for each dip. For the

329 EPGF, CC values for the Love wave 'stressgram' and tremor envelope occurs when the dip of

330 the fault increases (Figure 6a), for different locations and CC time windows (see Table 2). In

331 addition, the cross-correlation values do not vary much when computing the 'stressgram' for the

332 entire surface wave window at different source locations. This is possibly due to the fact that 
333 stress at depth does not change much for high angle dips when surface waves arrive almost

334 perfectly perpendicular to the fault strike (Figure S4). Thus, while the Coulomb triggering 335 potential model prefers a near-vertical fault $\left(\sim 90^{\circ}\right)$, the model is unable to distinctly resolve the 336 dip of the EPGF for this study.

337 We searched all possible dips that might explain triggering of the tremor on the reverse 338 PGJF as well (Figure 6c). For a fault dip of $\sim 55^{\circ}$ on the PGJF, the highest correlation between a 339 computed Love wave 'stressgram' and the tremor envelope occurs. However, this CC value is 340 still lower than when the surface wave stresses of the Chile mainshock are resolved onto a high341 angle $\left(>60^{\circ}\right)$ south-dipping EPGF. That is, the triggering potential is greatest for Love wave 342 triggering on a high-angle $\left(>60^{\circ}\right)$ south-dipping EPGF. In addition, it is possible that the fault

343 strike angles we assumed for the stress modeling may not be very accurate. To test this

344 uncertainty in our stress modeling, we calculated CC values by slightly changing the strike from

345 the original assumed values for both faults. We use $0^{\circ} \pm 15^{\circ}$ for EPGF (Figure 6b) and $125^{\circ} \pm 15^{\circ}$

346 for PGJF (Figure 6d), and in both cases, we observe that the variable strike angles do not change

347 the CC values significantly.

348 We offer one further note on using the triggering potential for testing fault orientation. In

349 this study, we treat locating the triggered tremor sources and estimation of fault orientation as

350 being independent of each other. However, estimation of fault orientation using the Coulomb

351 triggering potential largely depends on the location of the tremor sources. Therefore, we suggest

352 that future works could consider joint estimation of tremor location and fault orientation when

353 modeling transient stresses that trigger on unknown fault structures. 
(a)

(b)

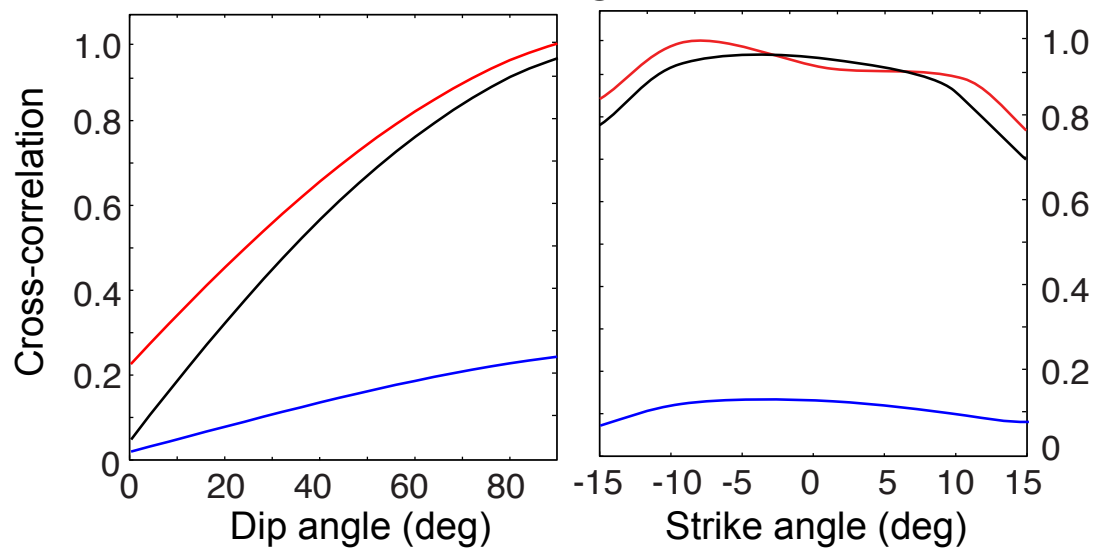

(c)

(d)

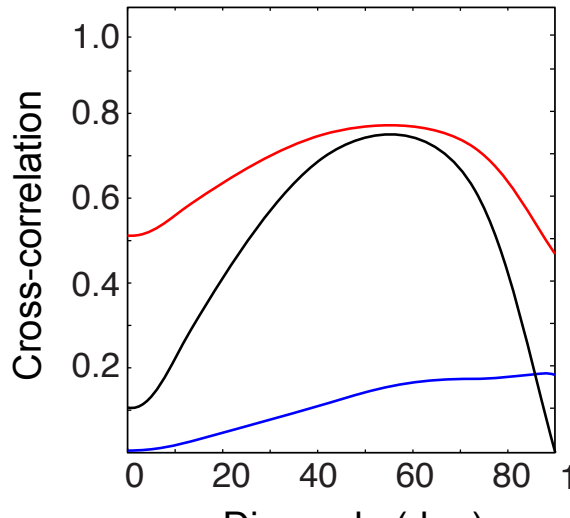

PGJF

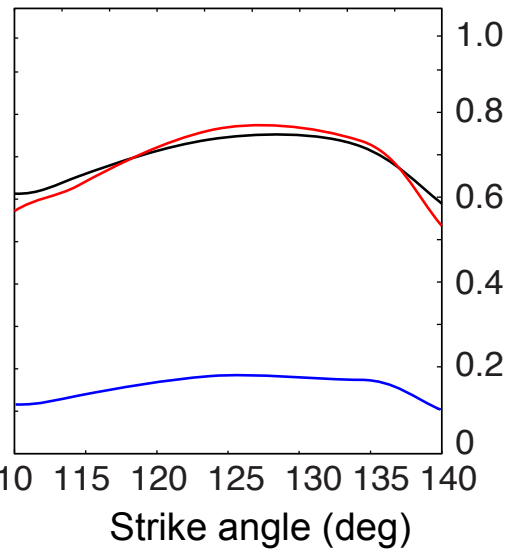

Dip angle (deg)

Strike angle (deg)

356 Figure 6. Cross-correlation values between tremor envelope and Love wave 'stressgram' (see Figure 5) computed for varied dip and strike angles, source locations, and time windows for the $(a-b)$ Enriquillo-Plantain Garden Fault (EPGF) and ( $c-d)$ Petit Goave-Jacmel Fault (PGJF). Black lines $=$ correlation values when the 'stressgram' is computed at the average tremor source location for the entire surface wave window (test \#1 in Table 1). Red lines = 'stressgram' computed at the burst \# 5 location for the entire surface wave window (test \# 2). Blue lines = only burst \# 5 location and its window (test \# 3). Correlation is greatest for a left lateral strikeslip EPGF with high-angle $\left(>60^{\circ}\right)$ dips.

\section{Search for triggered aftershock activity}

\subsection{Aftershock detection}

To investigate if aftershock activity of the Haiti mainshock was promoted by transient stress changes generated by the Chile mainshock, we applied a matched filter detection technique 
370 through 2 March 2010. This technique uses waveforms of known earthquakes as templates for

371 scanning through continuous seismic data in search of similar events, i.e. detections are made via

372 cross-correlations over numerous time windows. In this study, we utilized aftershocks detected

373 by the Canadian National Seismograph Network (CNSN) and Douilly et al. [2013] from 23

374 February through 2 March 2010 as template events. The aftershock catalog of Douilly et al.

375 [2013] does not contain event magnitudes, and so we compared events in their catalog to the

376 CNSN earthquake catalog that provides event magnitudes and used the CNSN magnitude, if

377 available. Not all aftershocks listed in Douilly et al. [2013] are also listed in the CNSN catalog

378 (and vice versa). Nonetheless, we utilized all earthquakes in these catalogs (with and without

379 magnitude) as templates.

$380 \quad$ For template event location, we assigned the locations of Douilly et al. [2013] where

381 applicable since in that study the hypoDD program [Waldhauser and Ellsworth, 2000] was used

382 to relocate aftershocks, making their locations more accurate than those listed in the CNSN

383 catalog. In total, we used 79 known earthquakes as templates for the matched filter detection.

384 Table S3 provides a summary of the origin time, location, and magnitude (if available) of those 385 templates.

386 After identifying templates from local earthquake catalogs, we cut the templates from 387 each channel for each day of seismic data that had been filtered to the 2-16 Hz frequency band.

388 Then, each channel's template was cross-correlated with the same channel's 24 -hr seismic record

389 from 23 February through 2 March 2010, shifting in time. The highest mean cross-correlation

390 value (CC) across all channels above 9 times the median absolution deviation (MAD) was taken

391 as the $\mathrm{CC}$ value for the detected earthquake (e.g., Figure 7). After detecting earthquakes using

392 the template events, we removed duplicate detections and verified that there were no false 
393 detections by examining the waveforms of each detected earthquake. For a more detailed 394 description of how we performed the matched filter detection, please refer to Appendix A.

395

396

397

398

399

400

401

402 
(a)

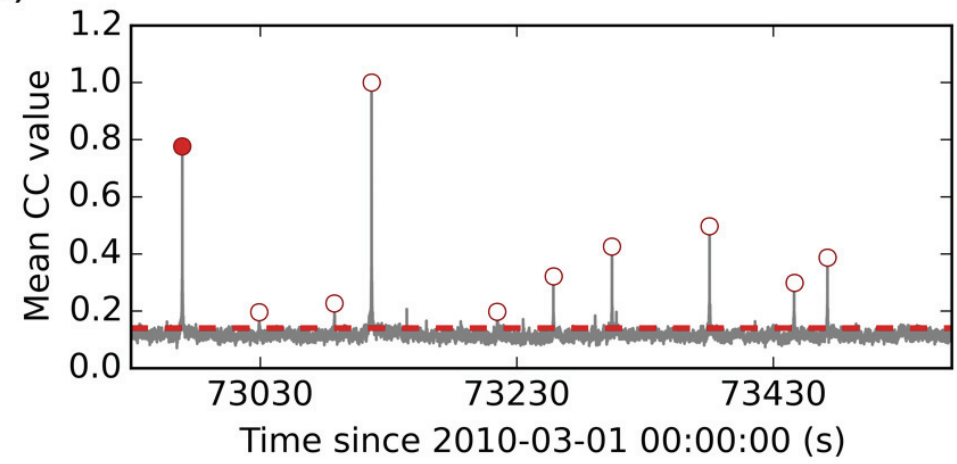

(b)

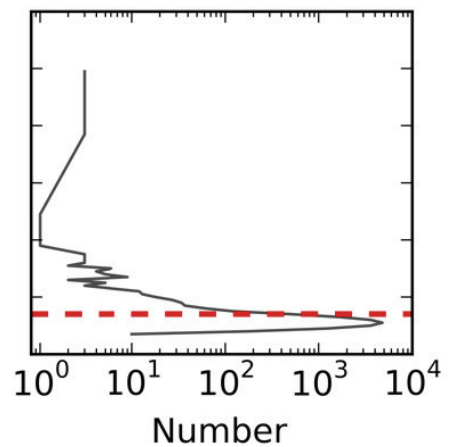

(c)

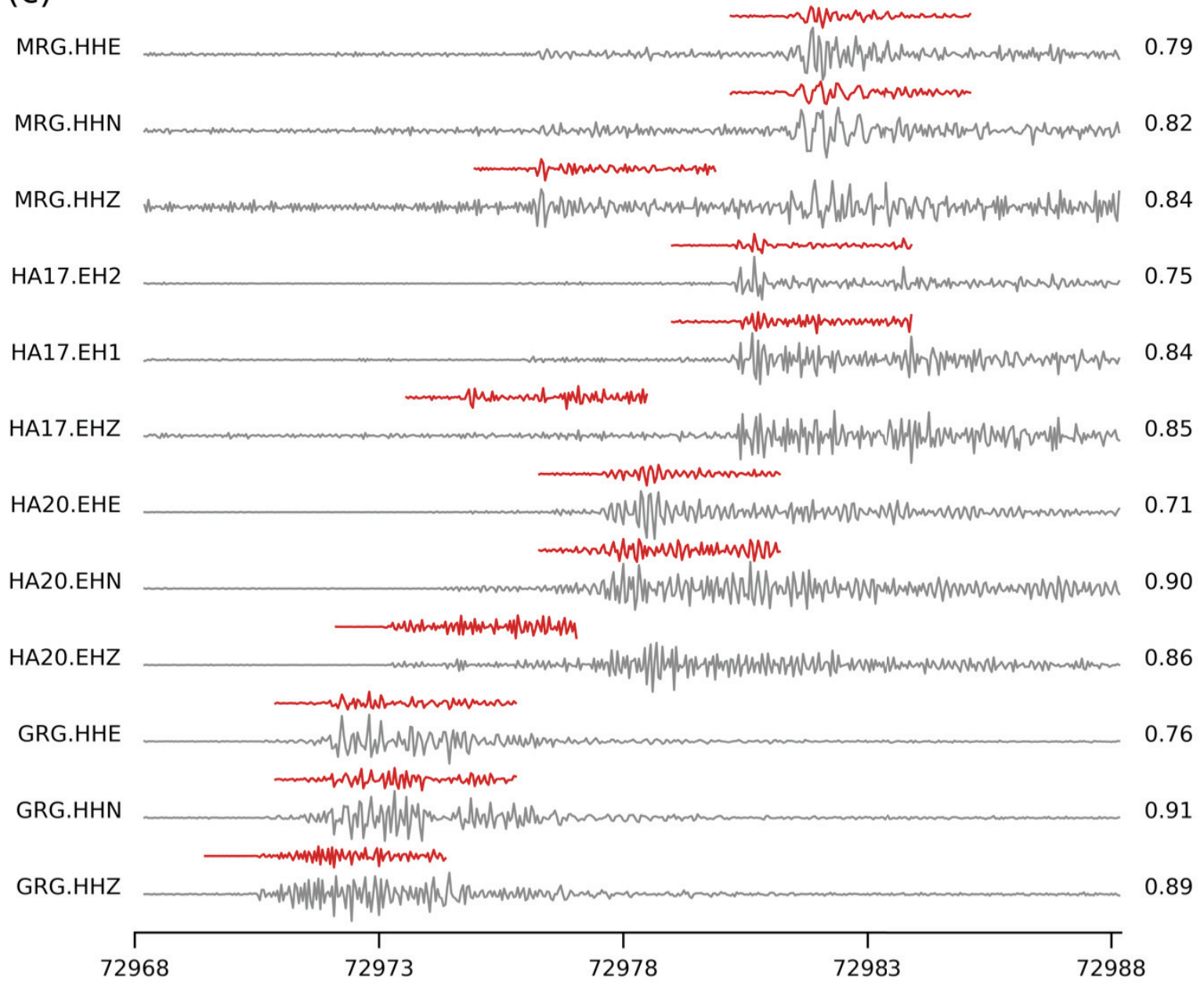

Time since 2010-03-01 00:00:00 (s)

404 Figure 7. Example of a Haiti aftershock detected using the matched filter technique. (a) Mean cross-correlation function created from stacking cross-correlation functions across all channels. Dashed red line marks 9 times the median absolute deviation (MAD) of the correlation trace, which is used as a threshold for avoiding false detections. Circles mark detections. (b) Histogram 408 of the mean CC function. (c) Comparisons between continuous (gray) and template waveforms 
421 (Figure 8a). value, a simple statistical test of rate change which contrasts the observational time windows

432 before and after an event to the number of event occurrences detected in those time windows. It 433 is known that the $Z$ value is less dependent upon the sample size compared to the $\beta$ statistical test 434 and is computed as

(red) at a few station-channel pairs (e.g., GRG.HHZ) and their corresponding correlation value (marked on the right) for the detection marked as solid red in (a). A CC value of 1 is when a template detects itself (i.e., a self-detection).

\subsection{Aftershock observations}

From 23 February through 2 March 2010, we detected a total of 1,829 earthquakes using templates with and without known magnitude. The magnitude of completeness $M_{c}$, which describes the lower magnitude limit the local seismic network can detect, was 1.5 for our detection catalog (Figure 8b). A $M_{c}$ of 1.5 is 0.6 less than the CNSN catalog $M_{c}$ (Figure S5). Considering only detected events with $M \geq M_{c}=1.5$, we observed $\sim 10$ times the number of events listed in the CNSN catalog for the same time period using the matched filter technique an increase in aftershock activity might have occurred in the first few days following the Chile mainshock, including two $\mathrm{M} \sim 3$ earthquakes that occurred immediately after the $P$-wave of the Chile mainshock (Figure 2). To examine this further, we first computed the seismicity rate from sliding time windows [e.g., Ziv et al., 2003; Felzer and Brodsky, 2006] using events in our detection catalog with a cutoff magnitude of $M \geq M_{c}=1.5$. We observed that the median seismicity rate increased from 63 events day $^{-1}$ before to 78 events day ${ }^{-1}$ after the Chile mainshock (Figure 8c).

We further tested whether these changes in seismicity rate were significant using the $Z$ 


$$
Z=\frac{N_{a} T_{b}-N_{b} T_{a}}{\sqrt{N_{a} T_{b}^{2}+N_{b} T_{a}^{2}}}
$$

436 where $T_{a}$ is the length of the triggering time window, $T_{b}$ is the length of the background 437 seismicity window, and $N_{a}$ and $N_{b}$ are the number of event occurrences in the specified time 438 windows [Marsan and Wyss, 2011]. We verified the robustness of the $Z$ value by using different 439 time windows (from 6 to 72 hours) and by randomly sampling the background seismicity (i.e., 440 before the Chile mainshock) from our detected catalog 100 times (Figure 8d). These tests 441 indicate that the increase in seismicity rate following the Chile mainshock is significant $(Z>2)$

442 when the background window is larger. However, when the cutoff magnitude for the catalog is 443 varied $(1 \leq M \leq 2.5)$ and $Z$ values recalculated, the seismicity rate increase following the Chile 444 mainshock is only significant for a cutoff magnitude $M \leq 1.5$ and not for larger cutoff 445 magnitudes (Figure S6). However, we note that by varying the cutoff magnitude for the $Z$ value 446 tests, we inherently alter our sample size and therefore our significance estimate.

447 We also tested the significance of Haiti aftershock triggering by examining the spatial 448 distribution of events around the time of the Chile mainshock. We compute $Z$ values for \pm 3 days 449 around the Chile mainshock in $0.02^{\circ} \times 0.02^{\circ}$ degree bins over the entire Haiti region at different 450 magnitude thresholds (Figure S7). With or without a magnitude threshold $(1 \leq M \leq 2.5)$, there 451 were fewer triggered $(Z>2)$ areas than non-triggered areas, i.e. $4 \%$ or less of active spatial bins 452 experienced a 95\% confidence increase in earthquake activity. 
(a)

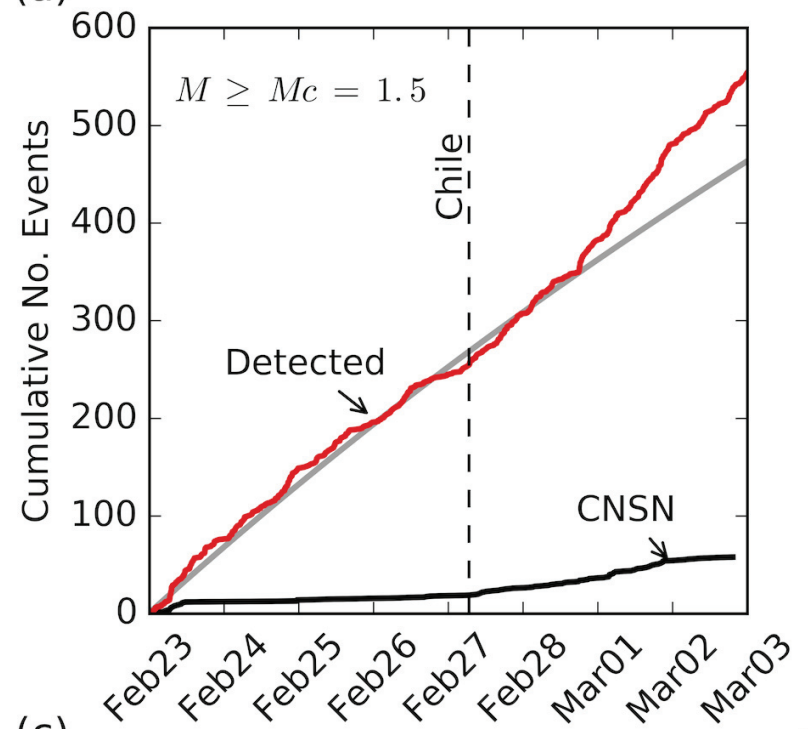

(c)

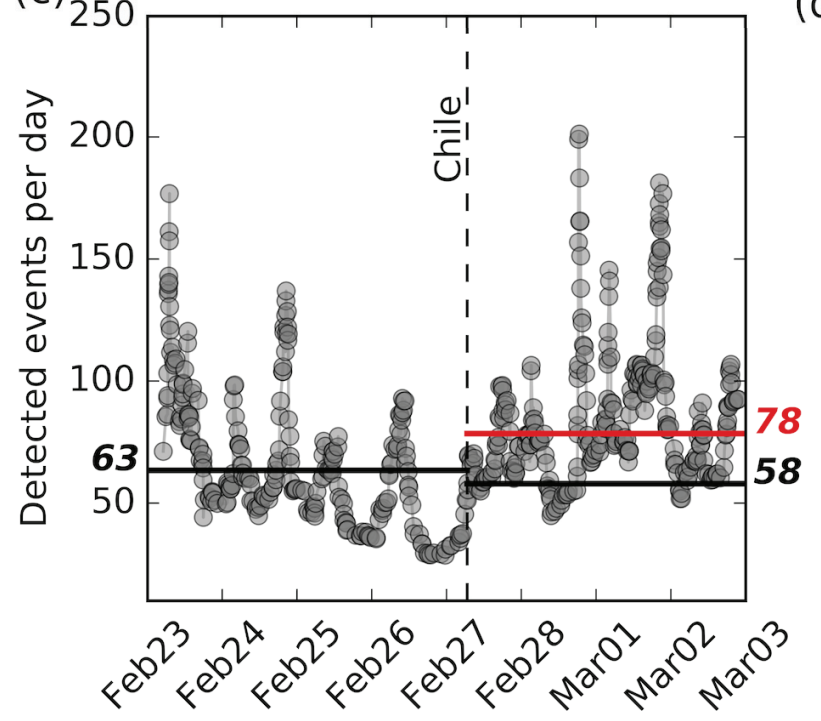

(b)

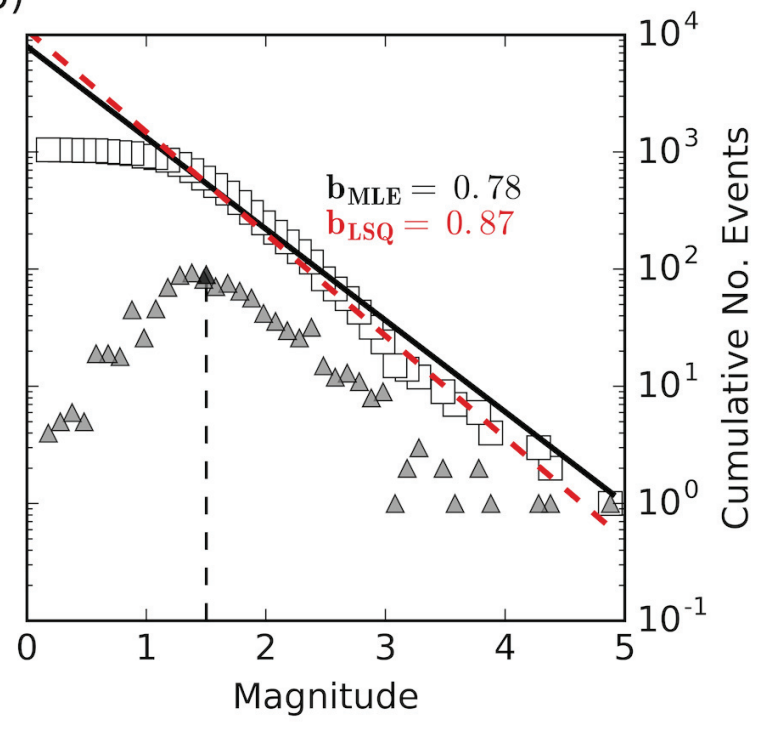

(d)

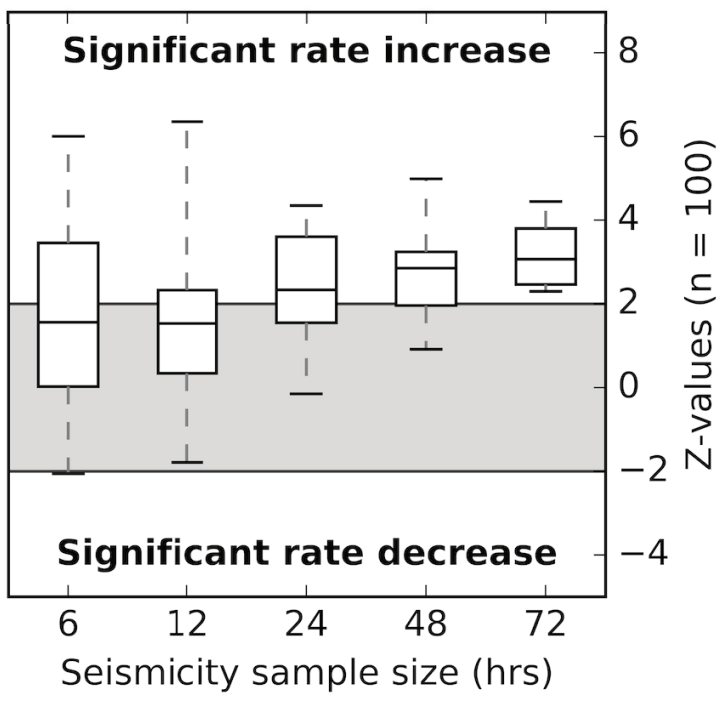

Figure 8. Summary of aftershock detection and seismicity rates around the time of the Chile mainshock. (a) Comparison of events with $M \geq 1.5$ in CNSN catalog and our detection catalog. Douilly et al. [2013] catalog is excluded here because that catalog does not contain magnitude. Solid gray line marks cumulative number associated with the median detection background rate of 63 events day ${ }^{-1}$. (b) Gutenberg-Richter relationship $N=10^{(a-b M)}$ for our detection catalog from February 23 through March 2 (events without magnitude are excluded). Maximum likelihood and least square methods were used for $b$-value evaluation. (c) Median number of detected events day ${ }^{-1}$ (with $M \geq 1.5$ ) appears to increase from 63 to 78 after the Chile mainshock. Line showing 58 events day ${ }^{-1}$ marks approximate aftershock rate after the Chile mainshock estimated from Omori decay law with constant productivity $K$ and $p=1$. (d) $Z$ value distribution for varied background seismicity windows. Median $Z$ value is greater than 2 for larger background window sampling sizes, but $Z$ values were also found to depend upon cutoff magnitude (Figure S6). 


\section{Discussion and conclusion}

In this study, we investigated how seismic waves from the 27 February $2010 M w 8.8$

470 Maule, Chile earthquake triggered seismicity around the aftershock zone of the 12 January 2010

$471 M w 7.0$ Haiti earthquake. We examined seismic data from 25 stations (6 on land, 19 offshore) in

472 search of tremor and Haiti aftershocks possibly induced by the remote Chile earthquake. We

473 identified $\sim 10$ tremor bursts triggered instantaneously by the long period surface waves of the

474 Chile mainshock (Figure 3), the first observation of tremor in the southern Haiti peninsula. The 475 triggered tremor sources radiated in the $\sim 1-10 \mathrm{~Hz}$ frequency band (Figure 2 ) from just south of 476 the EPGF fault trace but had no clear migration pattern (Figure 4). Immediately following the 477 Chile earthquake, the Haiti aftershock rate increased slightly in the next few days (Figure 8), but 478 this increase in aftershock activity depends upon the choice of the cutoff magnitude (Figure S6), 479 and we, therefore, consider an increase in aftershock activity may have possibly occurred based 480 on the inclusion on small magnitude events in the significance tests.

For the tremor sources, our locations have horizontal errors of $\sim 5 \mathrm{~km}$ on average. The 482 location errors are either a result of using a 1D velocity model when 3D velocity variations exist, 483 or it could be due to the fact that a tremor signal may represent several low-frequency 484 earthquakes occurring in rapid succession [e.g., Shelly et al., 2007]. If the latter, then the 485 envelope cross-correlation method we used for locating the tremor sources is possibly providing 486 the average location of low-frequency earthquakes that occurred in rapid succession. We note 487 that the depths of the tremor sources are not well resolved, with the exception of tremor burst \# 5 488 (Figure S2), which had the highest amplitude compared to the other triggered tremor (Figure 3).

489 It is reasonable to assume that the accuracy of the envelope cross-correlation method for locating 490 tremor sources depends somewhat on amplitude. For instance, a known aftershock (starred in 
491 Table S3) located with the same envelope cross-correlation method (and seismic stations) and

492 using only its $S$-wave arrival was found to have nearly an identical horizontal and vertical

493 location (Figure S8) to that of Douilly et al. [2013] who used the hypoDD program for source

494 location. Of course, it cannot go without saying that earthquakes, which generally have larger

495 amplitude, also have clear impulsive arrivals (e.g., Figure 2), which likely makes it easier to

496 resolve their depths.

497 When the surface wave stresses of the Chile mainshock were resolved onto fault planes

498 parallel to the EPGF and PGJF, we found that the triggered tremor best correlates (Table 2) as a

499 source occurring on the down-dip extension of a high-angle strike-slip EPGF (Figures 4b and 6),

500 in accordance with the Coulomb failure criterion [Hill, 2012]. Field observations and aftershock

501 detections suggest that the EPGF has vertical to high-angle $\left(>60^{\circ}\right)$ dip toward the south [Prentice

502 et al., 2010; Douilly et al., 2013], which overlaps with the northern end of the tremor location

503 distribution (Figure 4). However, we note that others suggest the EPGF could dip to the north

504 [Nettles and Hjörleifsdóttir, 2010]. We also checked that the tremor might have occurred on the

505 south-dipping reverse PGJF, but the stress modeling for a tremor source on the PGJF yielded

506 somewhat lower CC values (Table 2). Despite this lower correlation, the tremor sources do

507 coincide well with low shear velocity anomalies along the PGJF [Douilly et al., 2016]. Low

508 shear velocity anomalies or high $V p / V s$ ratios are used as a means of detecting the presence of

509 fluid and often coincide with tremor locations [e.g., Shelly et al., 2006; Becken et al., 2011].

510 While our tremor locations coincide laterally with a low-velocity anomaly along the PGJF, the

511 low-velocity anomaly occurs at $\sim 10 \mathrm{~km}$ depth, which is much shallower than the depths we

512 constrained for the tremor sources (Figure S2). 
513 Moreover, given the orientation of the studied faults relative to the surface waves

514 direction of propagation, Love waves will cause mainly shear stress changes while Rayleigh

515 waves will cause mainly normal stress changes [Gonzalez-Huizar and Velasco, 2011; Hill,

516 2012]. Thus, in a general approach, we can consider the 'stressgrams' of the Love and Rayleigh

517 waves (Figure 5) as a proxy to the total shear and normal stress changes, respectively. In

518 addition, given the relatively small amplitude of the Rayleigh wave from the Chile mainshock,

519 and thus, the small contribution of the normal stress changes to the triggering potential, we can

520 consider that the large shear stress changes, caused by the Love waves from the Chile

521 mainshock, were primarily responsible for triggering tremor in Haiti.

522 Shelly and Johnson [2011] showed that the M6.0 Parkfield earthquake ( 8 km depth)

523 induced $\sim 1 \mathrm{kPa}$ of static stress changes on the strike-slip San Andreas Fault at depths where

524 tremor occurs $(\sim 25 \mathrm{~km})$. Though small, these static stress changes increased tremor activity rates

525 by at most 2 orders of magnitude over a 30-day period in the Parkfield region. Therefore, one

526 may consider the possibility that the $2010 M w 7.0$ Haiti earthquake may have induced positive

527 static stress changes on the down-dip extension of the EPGF where we assume the triggered

528 tremor occurred in this study. Symithe et al. [2013] estimated that static stress increased by $\sim 20$

$529 \mathrm{kPa}$ at about $20 \mathrm{~km}$ depth on the EPGF due to the $M w 7.0$ Haiti earthquake, when assuming a dip

530 of $65^{\circ} \mathrm{S}$. Given that this static stress change is larger than the dynamic stress changes caused by

531 the Chile mainshock, it is possible that ambient tremor activity was encouraged on the down-dip

532 extension of the EPGF by the 2010 Mw7.0 Haiti earthquake. Unfortunately, we cannot

533 substantiate the effect of the Haiti earthquake on tremor activity rates immediately following the

534 mainshock because no research quality stations where in operation at that time. Moreover, while 
535 this static stress change is large, it decays quickly with increasing distance from the fault and is

536 unlikely to cause a large static stress change over the entire source area of the tremor.

537 We also applied the matched filter technique (e.g., Figure 7) to investigate the possibility

538 that the Chile mainshock induced Haiti aftershock activity. Based on our seismicity rate results,

539 an increase in seismicity could possibly have occurred after the Chile mainshock (Figure 8). This

540 increase is apparent only when taking into account small magnitude events over the entire study

541 region, with time being the only factor (Figure S6). In this case, our findings are generally

542 consistent with recent studies that small magnitude earthquakes are more easily triggered than

543 larger ones [Parsons et al., 2012]. Our findings also partially agree with induced seismicity

544 observations where larger magnitude events are often not present during the early stages of fluid

545 injection [Ellsworth, 2013]. However, we did not observe a broad spatial distribution of increase

546 in seismicity across the southern Haiti region even at small magnitudes (Figure S7) nor does

547 there appear to be any significance in delay of large magnitude $(M>2.5)$ events in the 3 days

548 following the Chile mainshock (Figure S5-S6). In addition, both the ANSS and CNSN reported

549 the next large earthquakes ( M4) occurred 3-4 weeks after the Chile mainshock passed through

550 the southern Haiti region.

551 We note that the Haiti aftershocks decay with time, while we assumed a constant activity

552 rate for the $Z$ value calculation (Figure 8 ). Hence, the obtained $Z$ value likely underestimates the

553 true rate changes after accounting for the Omori-law decay. If we assume the Omori-law decay

554 constant $p=1$ then aftershock rate is $r=K t^{-1}$, where $r$ is rate, $K$ is productivity, and $t$ is time

555 since the Haiti mainshock. Assuming $K$ is constant for the aftershock sequence and a pre-Chile

556 aftershock rate of 63 events day $^{-1}$ (Figure 8), the expected number of $M \geq 1.5$ aftershocks 2 days

557 after the Chile mainshock is $\sim 58$ events day ${ }^{-1}$, only a 7\% decay from $\sim 63$ events day ${ }^{-1}$. The 
558 detected seismicity rate for $M \geq 1.5$ aftershocks after the Chile mainshock is $\sim 78$ events day ${ }^{-1}$,

559 which is a $23 \%$ increase from $\sim 58$ events day ${ }^{-1}$. Therefore, there is a small possibility that Haiti

560 aftershock activity increased following the Chile mainshock, but the increase activity is not

561 broadly distributed across the southern Haiti peninsula (Figure S7). This is generally consistent

562 with recent studies - that tremor may be more easily triggered than microearthquakes both in

563 field [Aiken and Peng, 2014] and laboratory [Bartlow et al., 2012] settings. In general, these

564 findings are attributed to lower effective normal stress (weaker fault "clamping") at tremor depth

565 due to near lithostatic pore pressures [Thomas et al., 2009].

566 Since the matched filter technique is based on the waveform similarity between a

567 template event and a continuous waveform, the aftershocks we detected likely occurred very near

568 to the location of the template events. Most of these aftershocks occurred on secondary high-

569 angle reverse faults north of the EPGF (Figure 4b) [Douilly et al., 2013]. Most earthquake

570 triggering cases are observed in geothermal/volcanic environments undergoing extensional

571 tectonics [Hill and Prejean, 2015] or near fluid injection sites [van der Elst et al., 2013] and

572 rarely (if at all) within compressional tectonic regimes [Harrington and Brodsky, 2006; Hill,

573 2015]. As shown in Hill [2015], reverse faults are typically further from failure, but one would

574 expect that faults under positive static stress changes generated by a local mainshock would be

575 susceptible to dynamic stress changes as well. However, even the optimally oriented Trois Baies

576 Fault ( $\sim 45^{\circ}$ dip) which produced aftershocks was not reactivated, statistically speaking, by the $>$

$57710 \mathrm{kPa}$ of dynamic stress generated by the seismic waves of the Chile mainshock (Figure 5,

578 Figure 8). One other possible explanation is that at this time in the Haiti mainshock-aftershock

579 sequence larger fault patches had already released their stress and that only small fault patches

580 remained. Such a scenario offers an explanation for the seeming upper magnitude limit and 
581 dependency of the $Z$ value statistics on the cutoff magnitude when considering events in the 582 entire aftershock region (Figure S6).

583 Regardless of the type of seismic activity induced, investigating remote triggering is 584 important for understanding the fundamental physics of how faults rupture, and there are many 585 remaining questions regarding triggering and fault interaction at the local and global scale. For 586 example, is there a global aftershock zone that can be influenced by large, distant earthquakes, 587 and does an upper magnitude limit for remotely triggered earthquakes exist [e.g., Johnson et al.,

$5882015]$ ? In addition, where triggered tremor is discovered, does ambient tremor activity also occur

589 there, and if so, what does that ambient tremor activity tell us about large earthquake cycles [e.g.,

590 Wech and Creager, 2011]? These directions of research aimed at understanding earthquakes

591 cycles as well as the role of tremor in them are promising for mitigating the effects of future 592 earthquakes.

593

594 Appendix A. Matched filter detection

595 We performed the matched filter detection over several days of seismic data. First, we 596 applied a $2-16 \mathrm{~Hz}$ band-pass filter to the continuous waveforms, i.e. from 23 February through 2 597 March 2010. Next, we changed the sampling rate of all the continuous waveforms to be the same $598(50 \mathrm{~Hz})$ for ease of cross-correlation computation. The template events (Table S3) were then cut 599 from each channel of the continuous seismic data 30 seconds before and 120 seconds after the 600 origin time of the template. The $P$ - and $S$-wave arrivals of the template events were used as 601 markers for computing the signal-to-noise ratio (SNR) on the vertical and horizontal 602 components, respectively. For each component, the signal window is from 1 second before to 5 603 seconds after the corresponding body wave arrival, while the noise window is from 7 seconds 
604 before to 1 second before the $P$-wave arrival. The signal window for each body wave phase is 605 also used in the cross-correlation of the template with the continuous data.

606 We require that at least 9 channels have SNR $>5$ for a single template to perform the 607 cross-correlation between the template event and continuous seismic data. If this criterion is met, 608 then each template on each channel was cross-correlated with the corresponding channel for each 609 continuous day seismic recording, re-computing the cross-correlation value (CC) by sliding 610 every time sample. The $\mathrm{CC}$ value for each channel for a single template was then stacked and 611 averaged, and only events above 9 times the median absolute deviation (MAD) of the CC trace 612 were kept to insure no false detections. Duplicate detections were also removed, and only 613 detections with the highest $\mathrm{CC}$ value were kept.

614 We estimated the magnitude of detected earthquakes by computing the amplitude ratio 615 between the detected event and template event with known magnitude (Table S3). The amplitude 616 ratio is computed for all channels and the median amplitude ratio for a single detected event is 617 used for magnitude estimation. The magnitude is computed as

$$
M_{d}=M_{k}+\log _{10}(A R)
$$

619 where $M_{d}$ is detected event magnitude, $M_{k}$ is known template event magnitude, and $A R$ is the 620 amplitude ratio computed as described above. We did not compute the magnitude of events 621 detected with a template event without known magnitude. Figure S9 shows all detections made 622 with the matched filter technique without regard to magnitude and those with magnitude $\geq 1.5$.

623 Figure S10 shows earthquakes detections made on a waveform envelope from station JAKH \pm 2 624 hours around the Chile mainshock. 
Research groups from Géoazur and the Institut Français de Recherche pour l'Exploitation de la Mer (IFREMER) installed temporary short period and broadband ocean bottom seismometers, which have four components including a hydrophone. The Institut de Physique du Globe de Paris (IPGP) also temporarily deployed four 3-component broadband seismometers near the EPGF trace, and the Natural Resources Canada (NRCan) agency installed 2 broadband seismometers near Jacmel (station JAKH) and Port-au-Prince (station PAPH). Seismic data from the Géoazur and IFREMER research groups are not openly accessible. However, seismic data recorded at stations JAKH and PAPH of the CN network (NRCan agency) are openly accessible via the IRIS Data Management Center (http://www.iris.edu/dms/dmc/). In addition, seismic data collected by IPGP (stations PEM, MRG, PTG, and GRG of the YB network) are openly accessible via the International Federation of Digital Seismograph Networks webservices (http://portal.resif.fr/?FDSN-webservices). Chile aftershock information shown in Figure 3 is freely accessible at the North California Earthquake Data Center (www.ncedc.org). The seismic travel time TauP program is available at http://www.seis.sc.edu/taup/ (last accessed (July 5, 2016). For a more detailed summary of the station information, please refer to Table 1 of Douilly et al. [2013]. Figures 1, 3, 4, 7, 8 were made using Python 3.4.3 (open source). Figure 2, 5, 6 were made using MatLab (proprietary).

\section{Acknowledgments}

We thank Xiaofeng Meng for his guidance with performing the matched filter detection. We also thank Tom Parsons and Mike Brudzinski for useful comments on this manuscript. This material is based upon work supported by the National Science Foundation Graduate Research Fellowship for C.A. under Grant No. DGE-1148903 and two ARCS Foundation awards. Z.P. is supported by National Science Foundation CAREER Grant EAR-0956051. H. G-H. is supported by Southern California Earthquake Center (SCEC). SCEC is funded by NSF cooperative agreement EAR-1033462 and USGS cooperative agreement G12AC20038.

\section{References}

Aiken, C. and Z. Peng (2014), Dynamic triggering of microearthquakes in three geothermal regions of California, J. Geophys. Res., 119, 6992-7009, doi: 10.1002/2014JB011218.

Aiken, C., Z. Peng, and K. Chao (2013), Tremors along the Queen Charlotte Margin triggered by large teleseismic earthquakes, Geophys. Res. Lett., 40, doi:10.1002/grl.50220.

Aiken, C., J. P. Zimmerman, Z. Peng, and J. I. Walter (2015), Triggered seismic events along the Eastern Denali Fault in northwest Canada following the 2012 Mw7.8 Haida Gwaii, 2013 $M w 7.5$ Craig, and two $M w>8.5$ teleseismic earthquakes, B. Seismol. Soc. Am., 105, no. 2B, doi: $10.1785 / 0120140156$.

Bakun, W. H., C. H. Flores, and U. S. ten Brink (2012), Significant Earthquakes on the Enriquillo Fault System, Hispaniola, 1500-2010: Implications for Seismic Hazard, $B$. Seismol. Soc. Am., 102, no. 1, 18-30, doi: 10.1785/0120110077. 
Bartlow, N. M., D. A. Lockner, and N. M. Beeler (2012), Laboratory triggering of stick-slip events by oscillatory loading in the presence of pore fluid with implications for physics of tectonic tremor, J. Geophs. Res., 117, B11411, doi: 10.1029/2012JB009452.

Becken, M., O. Ritter, P. A. Bedrosian, and U. Weckmann (2011), Correlation between deep fluids, tremor and creep along the central San Andreas fault, Nature, 480, 87-90, doi: 10.1038 /nature10609.

Beroza, G. C. and S. Ide (2011), Slow earthquakes and nonvolcanic tremor, Annu. Rev. Earth Planet. Sci., 39, 271-296, doi 10.1146/annurev-earth-040809-152531.

Brodsky, E. E. and S. G. Prejean (2005), New constraints on mechanisms of remotely triggered seismicity at Long Valley Caldera, J. Geophys. Res., 110, B04302, doi:10.1029/2004JB003211.

Brodsky, E. E., E. Roeloffs, D. Woodcock, I. Gall, and M. Manga (2003), A mechanism for sustained groundwater pressure changes induced by distant earthquakes, J. Geophys. Res., 108, No. B8, doi: 10.1029/2002JB002321.

Brodsky, E. E. and N. J. van der Elst (2014), The Uses of Dynamic Triggering, Annu. Rev. Earth Pl. Sc., 42, 317-339, doi: 10.1146/annurev-earth-060313-054648.

Calais, E., A. Freed, G. Mattioli, F. Amelung, S. Jónsson, P. Jansma, S-H. Hong, T. Dixon, C. Prépetit, and R. Momplaisir (2010), Transpressional rupture of an unmapped fault during the 2010, Haiti earthquake, Nat. Geosci., 3, doi:10.1038/ngeo992.

Chao, K., and K. Obara (2016), Triggered Tectonic Tremor in Various Types of Fault Systems of Japan Following the 2012 Mw8.6 Sumatra Earthquake, J. Geophys. Res., 120, doi:10.1002/2015JB012566.

Chao, K., Z. Peng, H. Gonzalez-Huizar, C. Aiken, B. Enescu, H. Kao, A. A. Velasco, K. Obara, and T. Matsuzawa (2013), A global search for triggered tremor following the $2011 \mathrm{Mw} 9.0$ Tohoku earthquake, B. Seismol. Soc. Am., 103, no. 2B, doi: 10.1785/0120120171.

Douilly, R., J. S. Haase, W. L. Ellsworth, M. P. Bouin, E. Calais, S. Symithe, J. G. Armbruster, B. Mercier de Lépinay, A. Deschamps, S. L. Mildor, M. Meremonte, and S. Hough (2013), Crustal Structure and Fault Geometry of the 2010 Haiti Earthquake from Temporary Seismometer Deployments, B. Seismol. Soc. Am., 103, no. 4, 2305-2325, doi: 10.1785/0120120303.

Ellsworth, W. L. (2013), Injection-induced earthquakes, Science, 341, 1225942, doi: $10.11126 /$ science. 1225942 .

Felzer, K. and E. E. Brodsky (2006), Decay of aftershock density with distance indicates triggering by dynamic stress, Nature, 441, 735-738, doi: 10.1038/nature04799. 
Fry, B., K. Chao, S. Bannister, and Z. Peng (2011), Deep tremor beneath the Hikurangi margin in New Zealand triggered by the 2010 Mw8.8 Chile earthquake, Geophys. Res. Lett, 38, L15306, doi:10.1029/2011GL048319.

Gomberg, J. and S. Prejean (2013). Triggered tremor sweet spots in Alaska, J. Geophys. Res., 118, 6203-6218, doi :10.1002/2013JB010273.

Gonzalez-Huizar, H. and A. A. Velasco (2011), Dynamic triggering: Stress modeling and a case study, J. Geophys. Res., 116, B02304, doi: 10.1029/2009JB007000.

Harrington, R. M., and E. E. Brodsky (2006), The absence of remotely triggered seismicity in Japan, B. Seismol. Soc. Am., 96 (3): 871-878, doi: 10.1785/0120050076.

Hill, D. P. (2012), Surface wave potential for triggering tectonic (non-volcanic) tremor -Corrected, B. Seismol. Soc. Am., 102, no. 6, 2313-2336, doi:10.1785/0120120085.

Hill, D. P. (2015), On the sensitivity of transtensional versus transpressional tectonic regimes to remote dynamic triggering by Coulomb failure, B. Seismol. Soc. Am., 105, no. 3, 1339-1348, doi: 10.1785/0120140292.

Hill, D. P., Z. Peng, D. R. Shelly, and C. Aiken (2013), S-wave triggering of tremor beneath the Parkfield, California, section of the San Andreas fault by the 2011 Tohoku, Japan, earthquake: Observations and theory, B. Seismol. Soc. Am., 103, no. 2B, doi: $10.1785 / 0120120114$.

Hill, D. P. and S. G. Prejean (2015), Dynamic Triggering, in Treatise on Geophysics $2^{\text {nd }}$ edition (G. Schubert, ed.), Chapter 8 in Volume 4, "Earthquake Seismology" (H. Kanamori, ed.), Elsevier, Amsterdam.

Hough, S. E., L. Seeber, and J. G. Ambruster (2003), Intraplate triggered earthquakes: Observations and Interpretation, B. Seismol. Soc. Am., 93, no. 5, 2212-2221.

Houston, H. (2015), Low friction and fault weakening revealed by rising sensitivity of tremor to tidal stress, Nat. Geosci., 8, 409-415, doi: 10.1038/ngeo2419.

Jiang, T., Z. Peng, W. Wang, and Q.-F. Chen (2010), Remotely triggered seismicity in Continental China by the 2008 Mw7.9 Wenchuan earthquake, B. Seismol. Soc. Am., 100, no. 5B, 5274-5289, doi: 10.1785/0120090286.

Johnson, C. W., R. Bürgmann, F. F. Pollitz (2015), Rare dynamic triggering of remote $\mathrm{M} \geq 5.5$ earthquakes from global catalog analysis, J. Geophys. Res., 130, no. 3, 1748-1761, doi: 10.1002/2014JB011788.

Kilb, D., G. Blasi, J. Anderson, J. Brune, Z. Peng, and F. Vernon (2012), Listen, watch, learn: SeisSound video products, Seismol. Res. Lett., 83, no. 2, 281-286, doi: 10.1785/gssrl.83.2.287. 
Marsan, D. and M. Wyss (2011), Seismicity rate changes, Community Online Resource for Statistical Seismicity Analysis, doi: 10.5078/corssa-25837590. Available at http://www.corssa.org.

Meng, X., Z. Peng, and J. Hardebeck (2013), Seismicity around Parkfield correlates with static shear stress changes following the 2003 Mw6.5 San Simeon earthquake, J. Geophys. Res., 118, no. 7, 3576-3591, doi: 10.1002/jgrb.50271.

Mercier de Lépinay, B., A. Deschamps, F. Klingelhoefer, Y. Mazabraud, B. Delouis, V. Clouard, Y. Hello, J. Crozon, B. Marcaillow, D. Graindorge, M. Vallée, J. Perrot, M-P. Bouin, J-M. Saurel, P. Charvis, and M. St-Louis (2011), The 2010 Haiti earthquake: A complex fault pattern constrained by seismologic and tectonic observations, Geophys. Res. Lett., 38, L22305, doi:10.1029/2011GL049799.

Nettles, M. and V. Hjörleifsdóttir (2010), Earthquake source parameters for the 2010 January Haiti mainshock and aftershock sequence, Geophys. J. Int., 183, 375-380 doi: 10.1111/j.1365-246X.2010.04732.x.

Obara, K. (2002), Nonvolcanic deep tremor associated with subduction in southwest Japan, Science, 296, 1679-1681, doi: 10.1126/science.1070378.

Parsons, T., J. O. Kaven, A. A. Velasco, and H. Gonzalez-Huizar (2012), Unraveling the apparent magnitude threshold of remote earthquake triggering using full wave-field surface wave simulation, Geochem. Geophys. Geosy., 13, Q06016, doi: 10.1029/2012GC004164.

Peng, Z., C. Aiken, D. Kilb, D. Shelly, and B. Enescu (2012), Listening to the 2011 magnitude 9.0 Tohoku-Oki, Japan earthquake, Seismol. Res. Lett., 83, no. 2, 287-293, doi: 10.1785/gssrl.83.2.287.

Peng, Z. and J. Gomberg (2010), An integrative perspective of couple seismic and aseismic slow slip phenomena, Nat. Geosci., 3, 599-607, doi: 10.1038/ngeo940.

Peng, Z., H. Gonzalez-Huizar, K. Chao, C. Aiken, B. Moreno, and G. Armstrong (2013), Tectonic tremor beneath Cuba triggered by the Mw8.8 Maule and Mw9.0 Tohoku-Oki earthquakes, B. Seismol. Soc. Am., 103(1), doi: 10.1785/0120120253.

Peng, Z., D. R. Shelly and W. L. Ellsworth (2015), Delayed dynamic triggering of deep tremor along the Parkfield-Cholame section of the San Andreas Fault following the 2014 M6.0 South Napa earthquake, Geophys. Res. Lett., 42(19), 7916-7922, doi: $10.1002 / 2015$ GL065277.

Peng, Z., J. Walter, R. Aster, A. Nyblade, D. Wiens, and S. Anandakrishnan (2014), Antartic icequakes triggered by the 2010 Maule earthquake in Chile, Nat. Geosci., 7, 677-681, doi: 10.1038/NGEO2212. 
810

811

812

813

814

815

816

817

818

819

820

821

822

823

824

825

826

827

828

829

830

831

832

833

834

835

836

837

838

839

840

841

842

843

844

845

846

847

848

849

850

851

852

853

Peng, Z., C. Wu, and C. Aiken (2011), Delayed triggering of microearthquakes by multiple surface waves circling the Earth, Geophys. Res. Lett., 38, L04306, doi: 10.1029/2010GL046373.

Peng, Z. and P. Zhao (2009), Migration of early aftershocks following the 2004 Parkfield earthquake, Nat. Geosci., 2,. 877-881, doi: 10.1038/ngeo697.

Prejean, S. G., D. P. Hill, E. E. Brodsky, S. E. Hough, M. J. S. Johnston, S. D. Malone, D. H. Oppenheimer, A. M. Pitt, and K. B. Richards-Dinger (2004), Remotely triggered seismicity on the United States west coast following the Mw7.9 Denali Fault earthquake, B. Seismol. Soc. Am., 94, No. 6B, S348-S359, doi: 10.1785/0120040610.

Prentice, C. S., P. Mann, A. J. Crone, R. D. Gold, K. W. Hudnut, R. W. Briggs, R. D. Koehler and P. Jean (2010), Seismic hazard of the Enriquillo-Plantain Garden fault in Haiti inferred from paleoseismology, Nat. Geosci., 3, 789-793, doi: 10.1038/ngeo991.

Shelly, D. R., G. Beroza, S. Ide, and S. Nakamula (2006), Low-frequency earthquakes in Shikoku, Japan, and their relationship to episodic tremor and slip, Nature, 442, 188-191, doi: 10.1038/nature049031.

Shelly, D. R., W. L. Ellsworth, T. Ryberg, C. Haberland, G. S. Fuis, J. Murphy, R. M. Nadeau, and R. Bürgmann (2009), Precise location of San Andreas Fault tremors near Cholame, California using seismometer clusters: Slip on the deep extension of the fault?, Geophys. Res. Lett., 36, L01303, doi:10.1029/2008GL036367.

Shelly, D. R. and K. M. Johnson (2011), Tremor reveals stress shadowing, deep postseismic creep, and depth-dependent slip recurrence on the lower-crustal San Andreas fault near Parkfield, Geophys. Res. Lett., 38, L13312, doi: 10.1029/2011GL047863.

Shelly, D. R., G. C. Beroza, and S. Ide (2007). Non-volcanic tremor and low frequency earthquake swarms, Nature, 446-305-307, doi: 10.1038/nature05666.

Symithe, S. J., E. Calais, J. S. Haase, A. M. Freed, and R. Douilly (2013), Coseismic slip distribution of the 2010 M7.0 Haiti earthquake and resulting stress changes on regional faults, B. Seismol. Soc. Am., 103, no. 4, 2326-2343, doi: 10.1785/0120120306.

Thomas, A., R. M. Nadeau, and R. Bürgmann (2009), Tremor-tide correlations and nearlithostatic pore pressure on the deep San Andreas fault, Nature, 462, 1048-1051, doi: 10.1038 /nature 08654 .

Toda, S., J. Lin, and R. S. Stein (2011), Using the $2011 \mathrm{M}=9.0$ Tohoku earthquake to test the Coulomb stress triggering hypothesis and to calculate faults brought closer to failure, Earth Planets Space, 63, 1-6, doi: 10.5047/eps.2011.05.010. 
854 van der Elst, N. J., H. M. Savage, K. M. Keranen, and G. A. Abers (2013), Enhanced remote earthquake triggering at fluid-injection sites in the Midwestern United States, Science, 341, no. 6142 , pp. 164-167, doi: $10.1126 /$ science. 1238948 .

Velasco, A. A., S. Hernandez, T. Parsons, K. Pankow (2008), Global ubiquity of dynamic earthquake triggering, Nat. Geosci., 1, 375 - 379, doi:10.1038/ngeo204.

Waldhauser, F. and W. L. Ellsworth (2000), A double-difference earthquake location algorithm: Method and application to the northern Hayward fault, B. Seismol. Soc. Am., 90, 1353-1368, doi: $10.1785 / 0120000006$.

Wech and Creager (2011), A continuum of stress, strength and slip in the Cascadia subduction zone, Nat. Geosci., 4, 624-628, doi: 10.1038/ngeo1215.

Zigone, D., D. Rivet, M. Radiguet, M. Campillo, C. Voisin, N. Cotte, A. Walpersdorf, N. Shapiro, G. Cougoulat, P. Roux, V. Kostoglodov, A. Husker, J. S. Payero (2012). Triggering of tremors and slow slip event in Guerrero, Mexico, by the 2010 Mw8.8 Maule, Chile, earthquake, J. Geophys. Res., 117, no. B9, doi: 10.1029/2012JB009160.

Ziv, A., A. M. Rubin, and D. Kilb (2003), Spatiotemporal analyses of earthquake productivity and size distributation: Observations and simulations, B. Seismol. Soc. Am., 93, no. 5, 20692081, doi: $10.1785 / 0120020117$. 


\section{Figures}

Figure 1

(a)

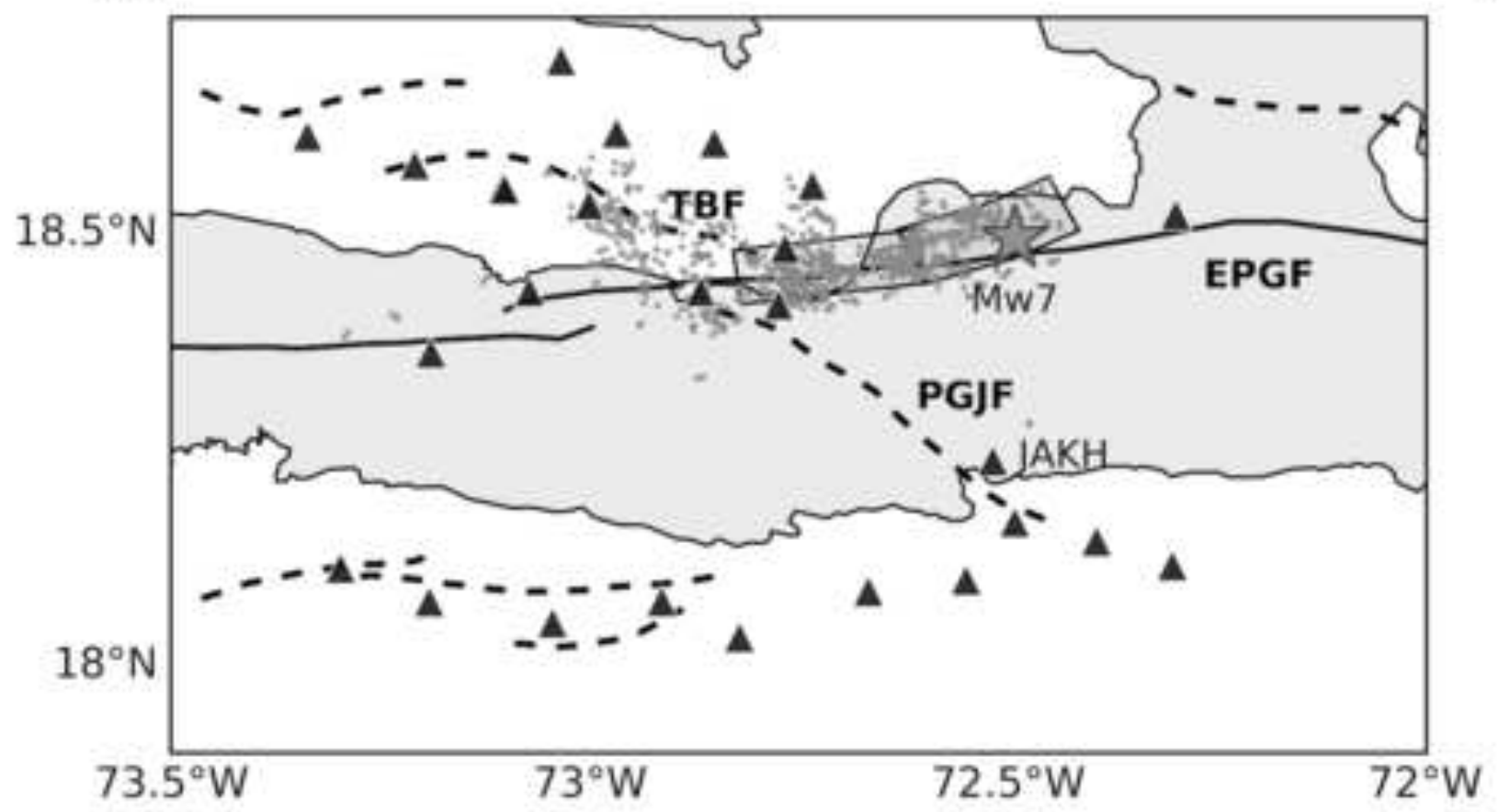

(b)

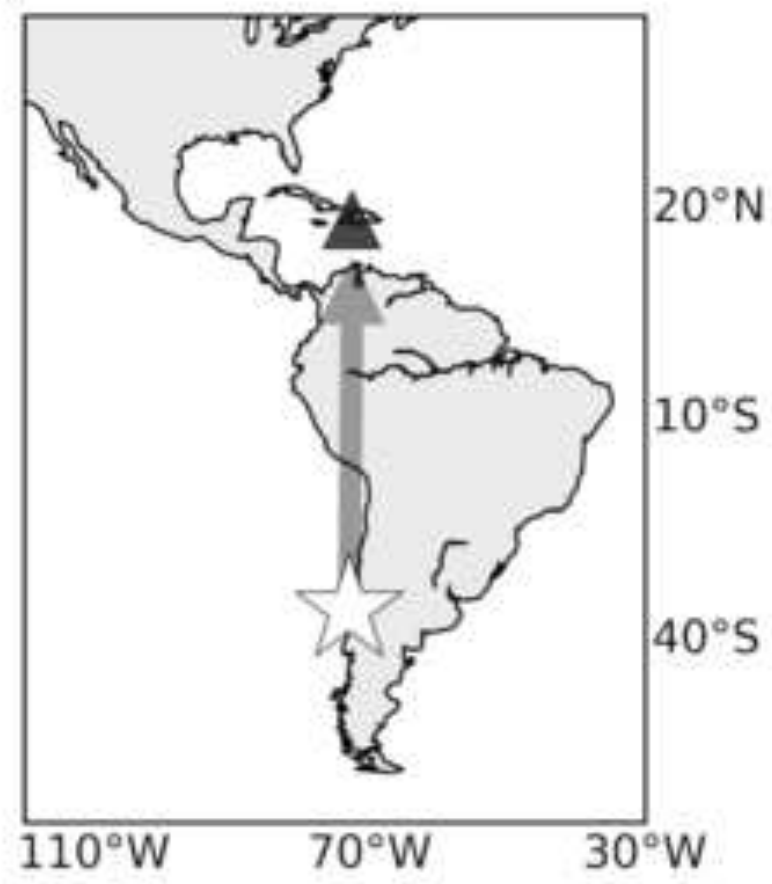

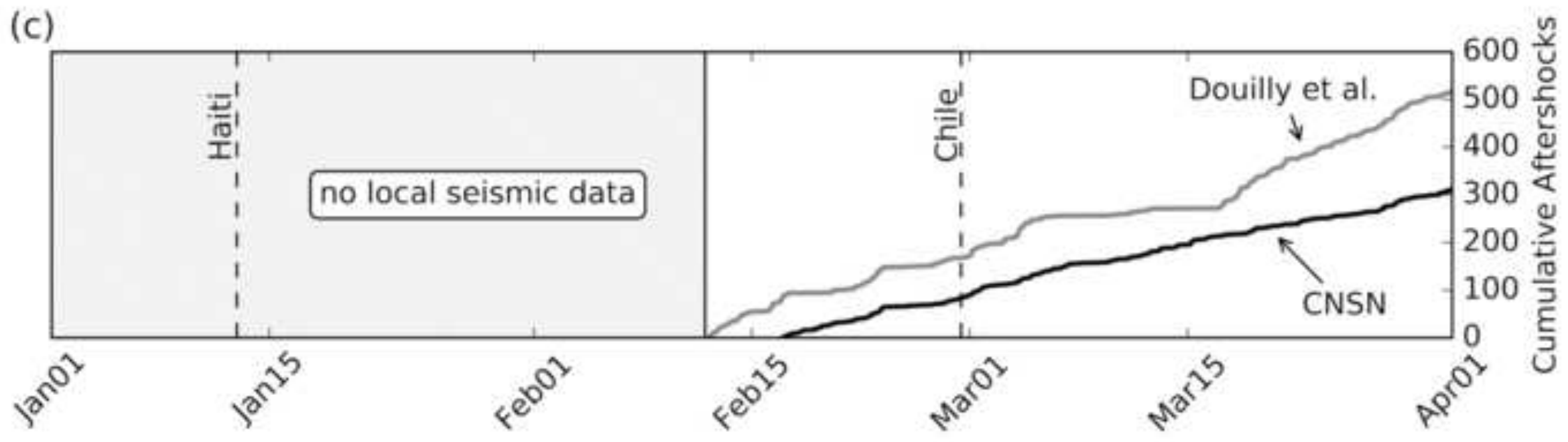


(a)

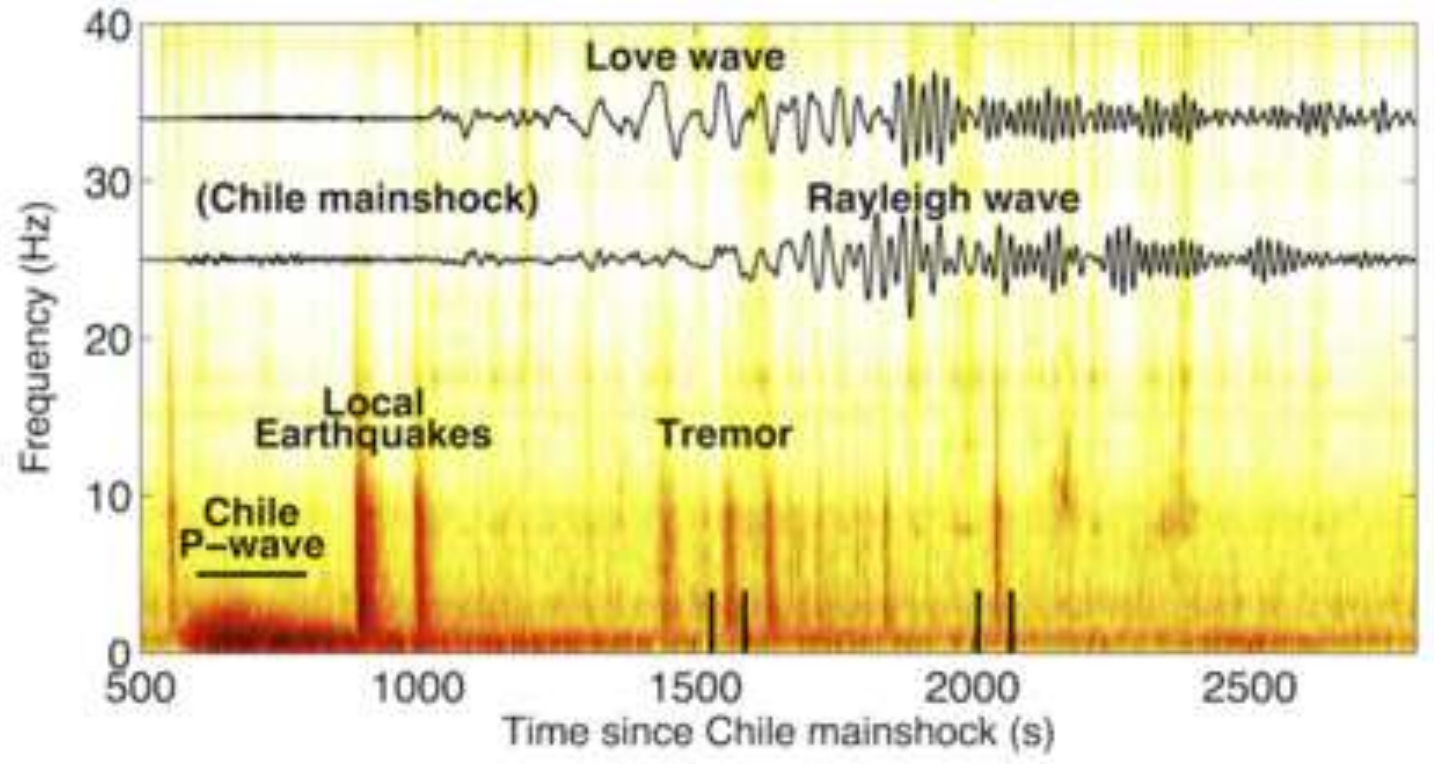

(b)

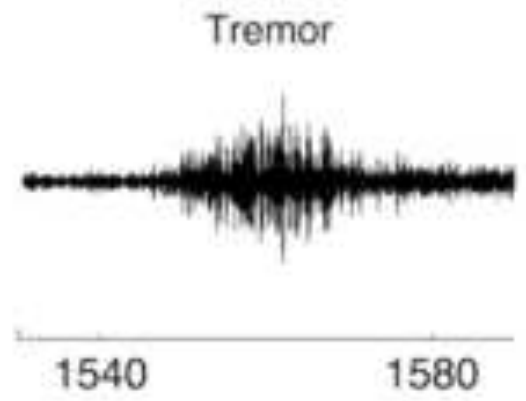

(c)

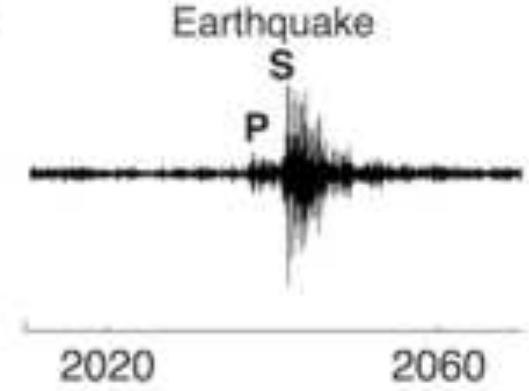




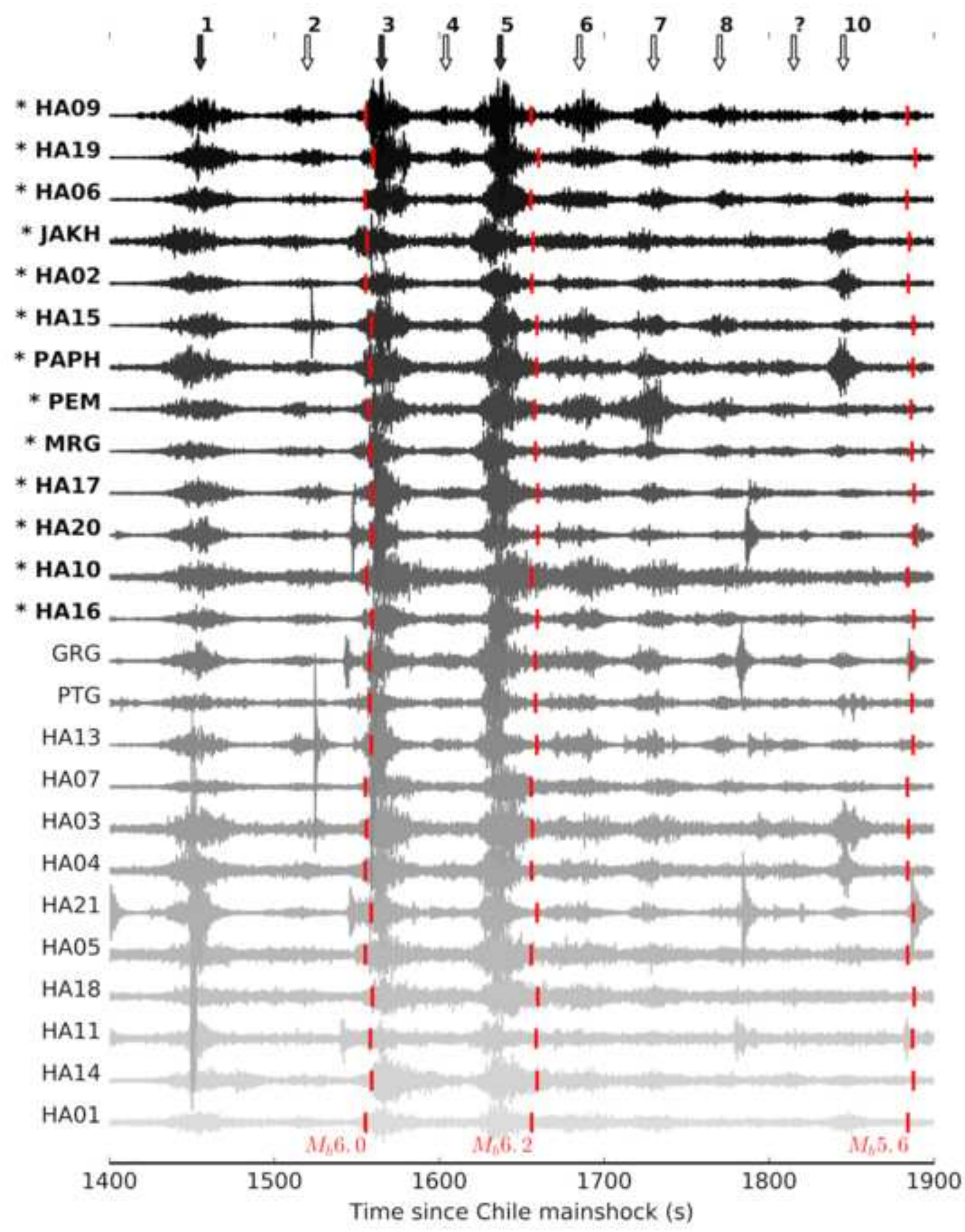

1400

1500

Time since Chile mainshock (s)

Figure 
(a)

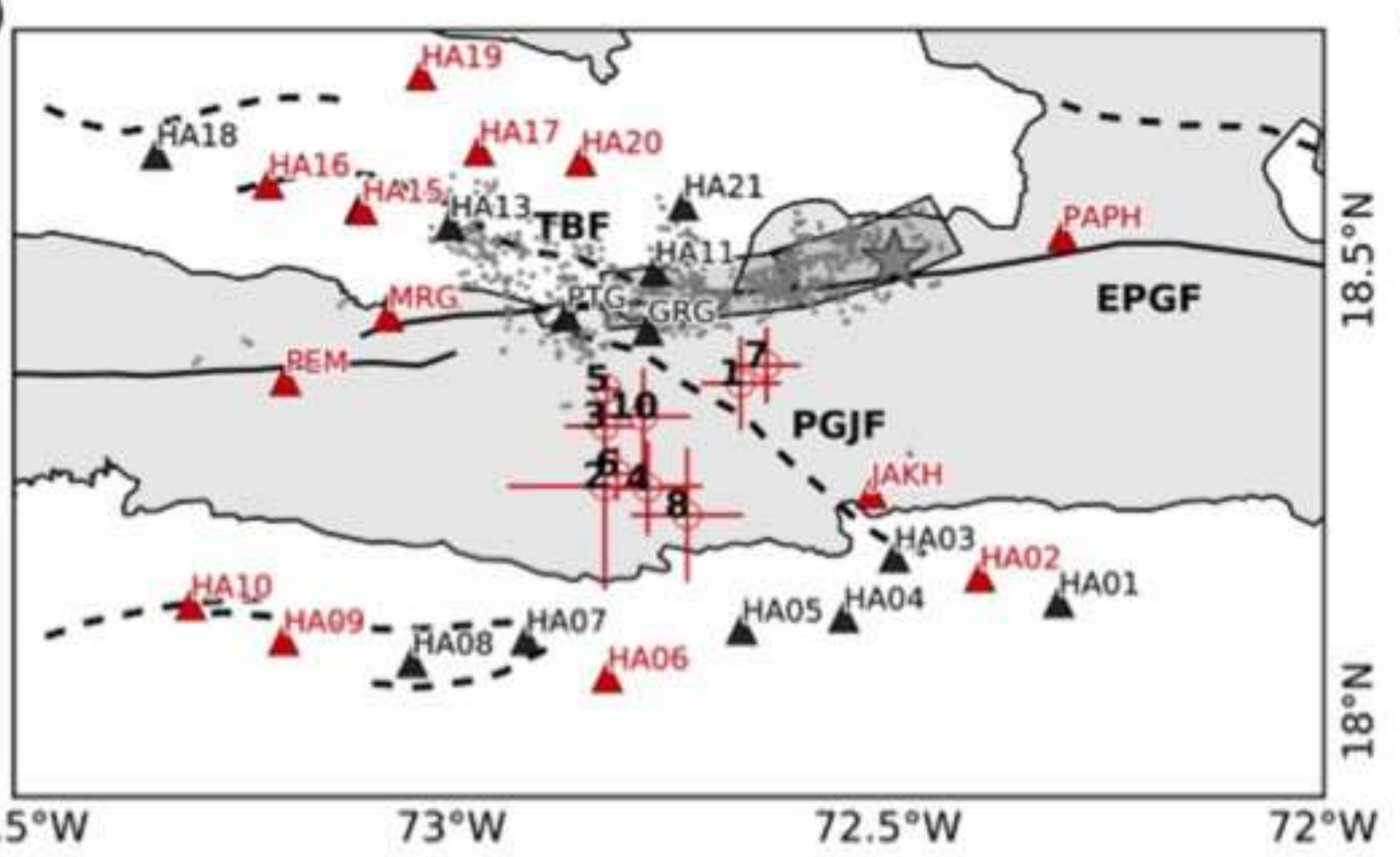

(b)

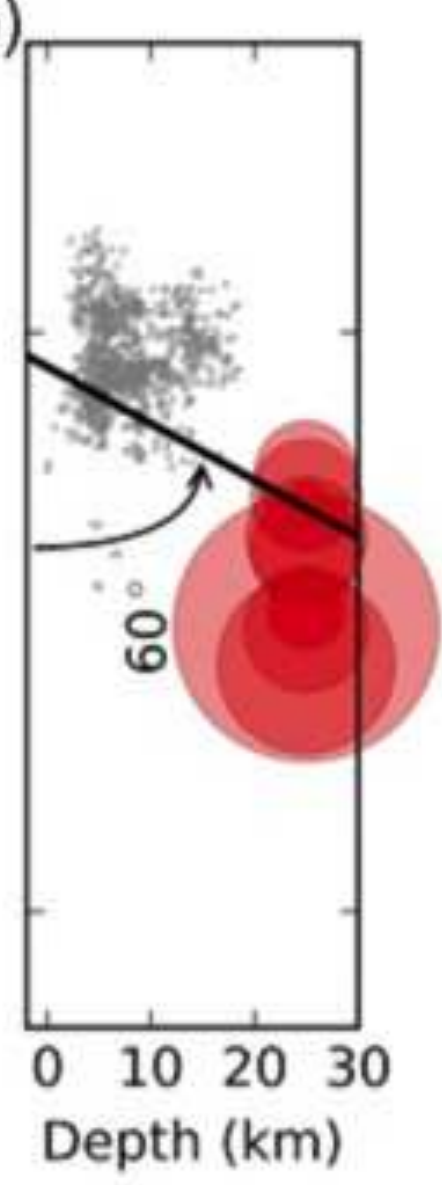

(c)

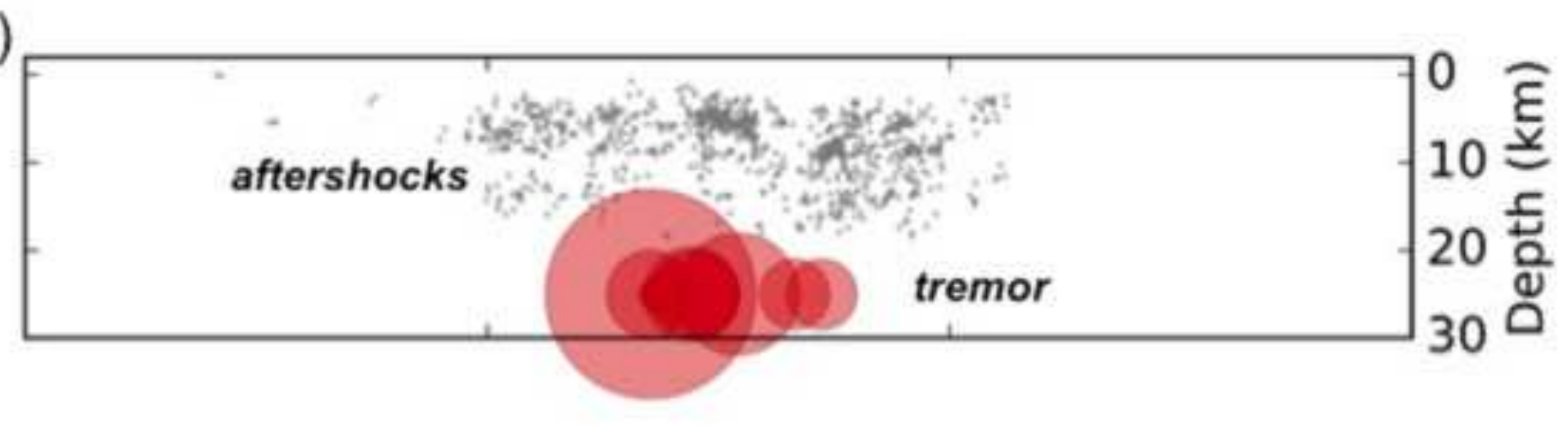

\section{$73.5^{\circ} \mathrm{W}$}


(a)

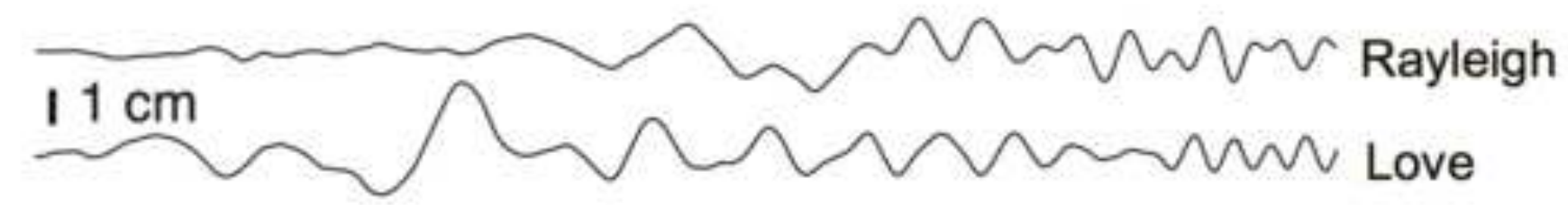

(b) Enriquillo-Plantian Garden Fault

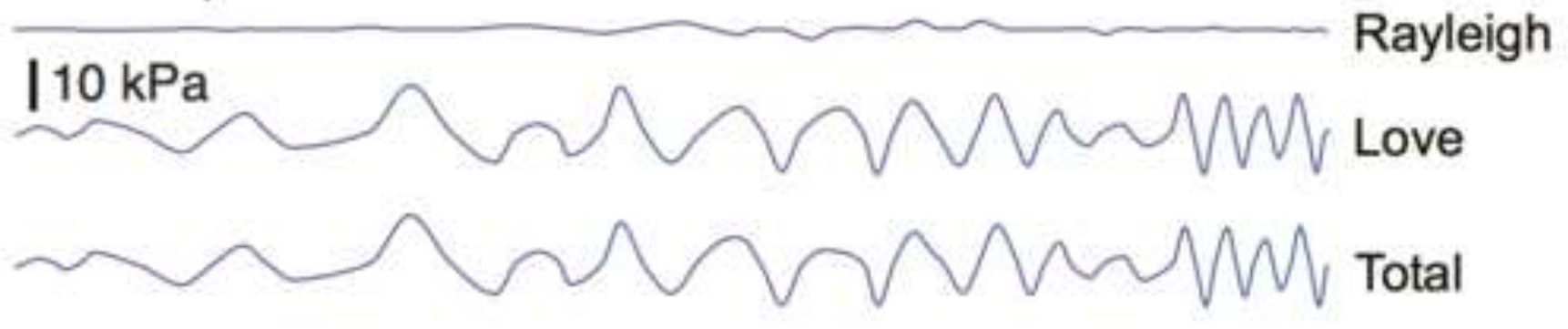

(c) Petit Goave-Jacmel Fault
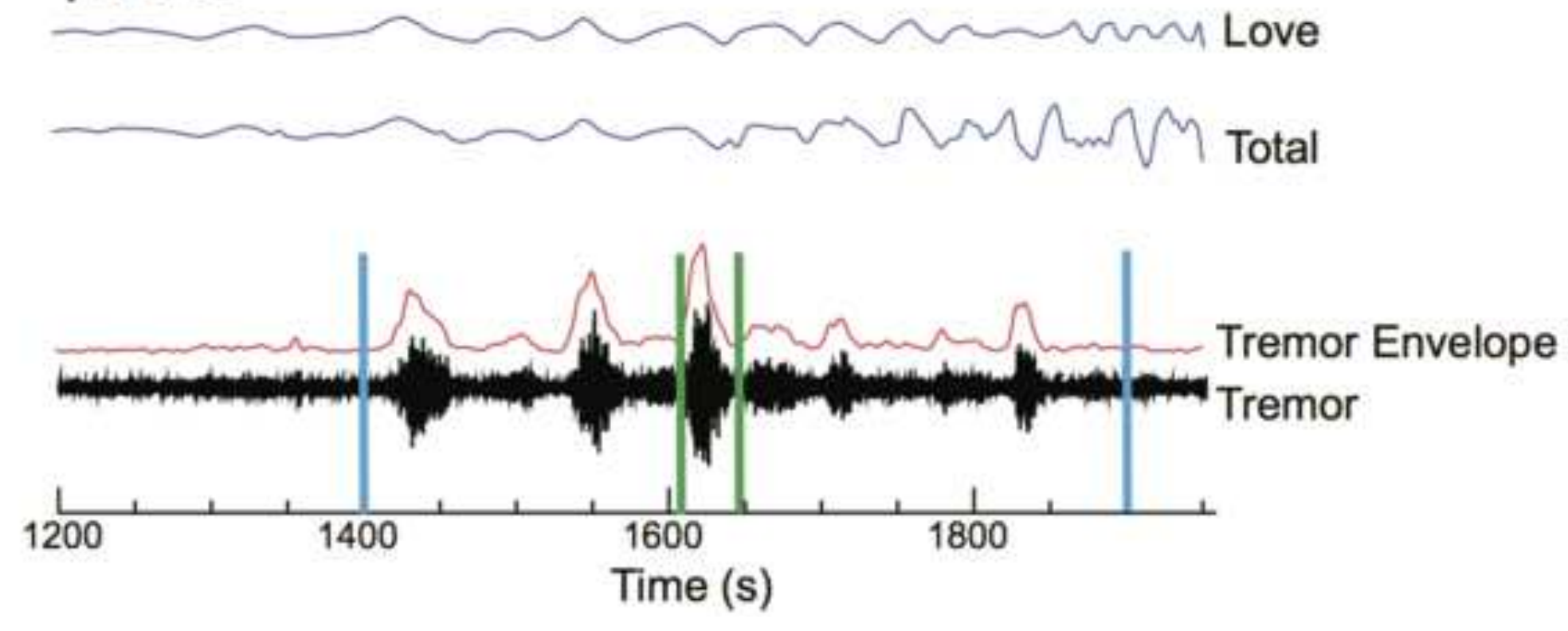


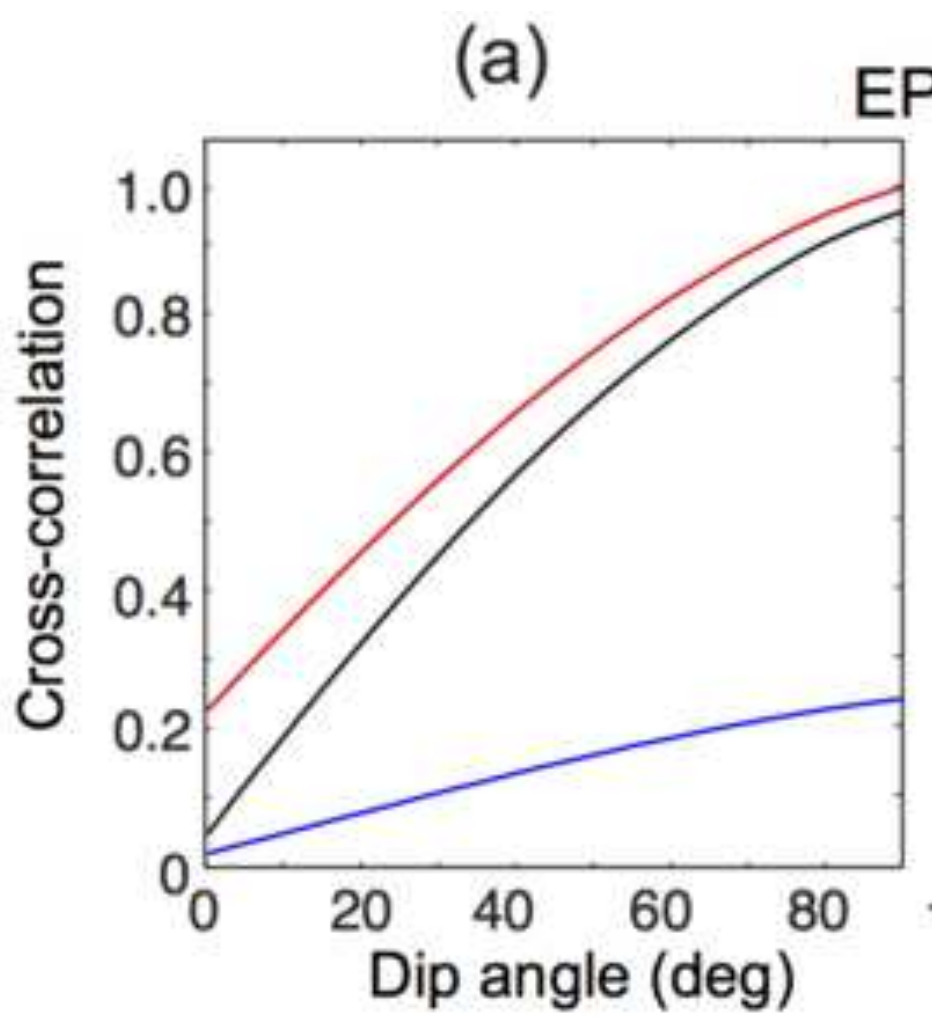

(c)

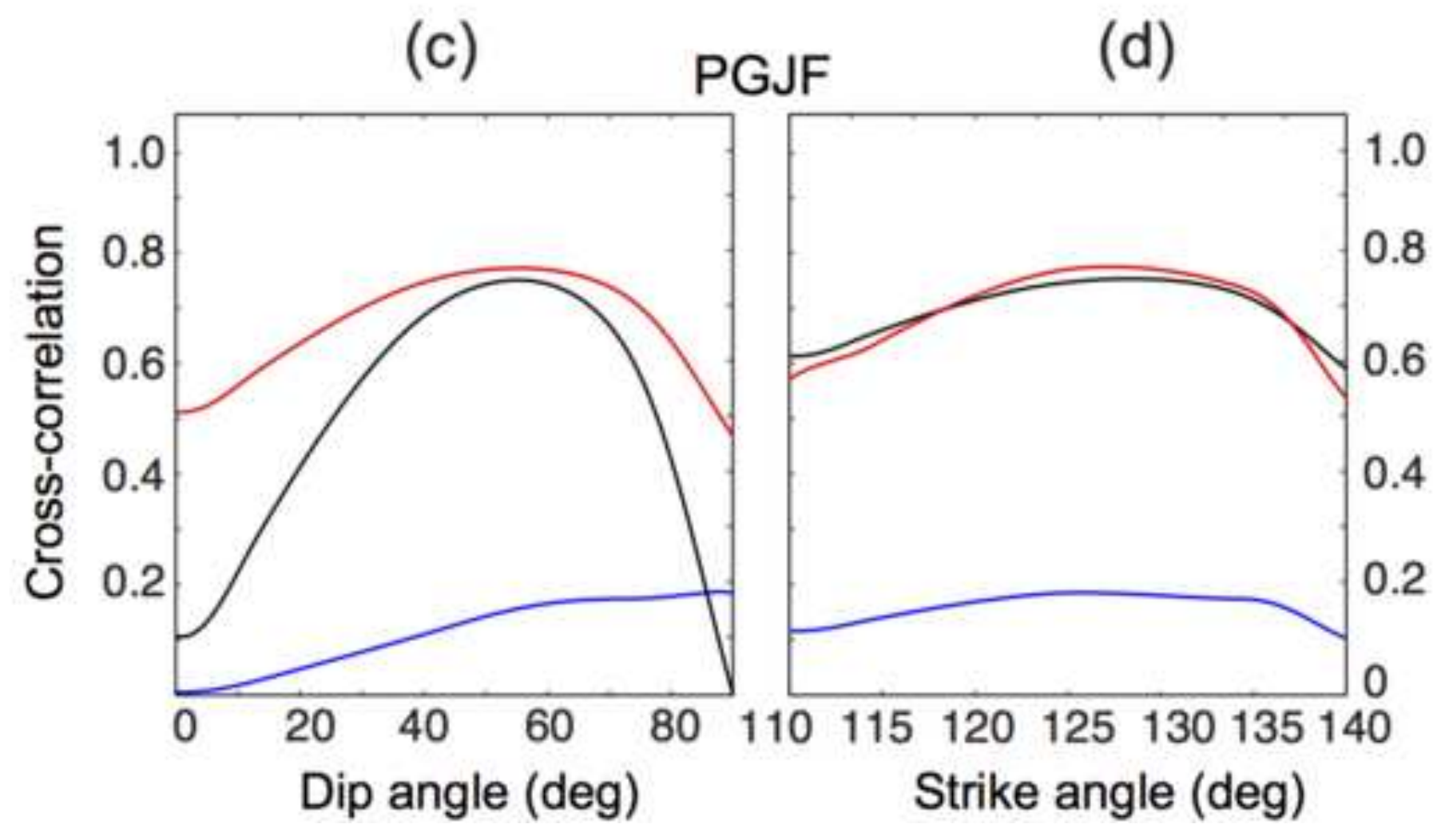

(b)

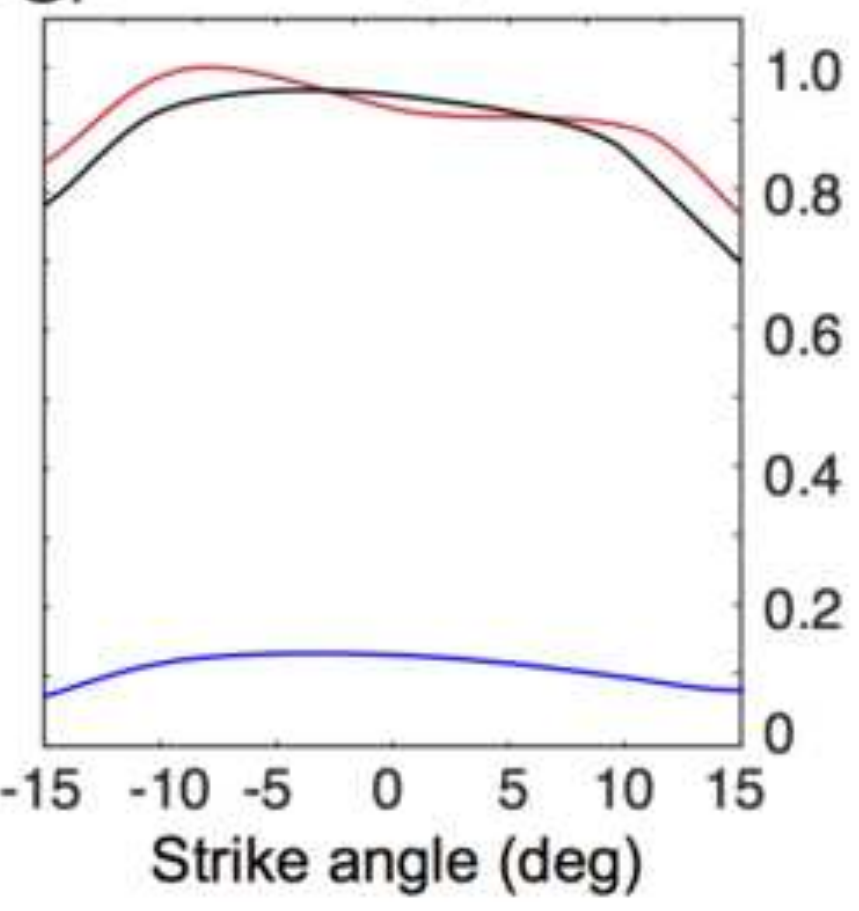

(d) 
(a)

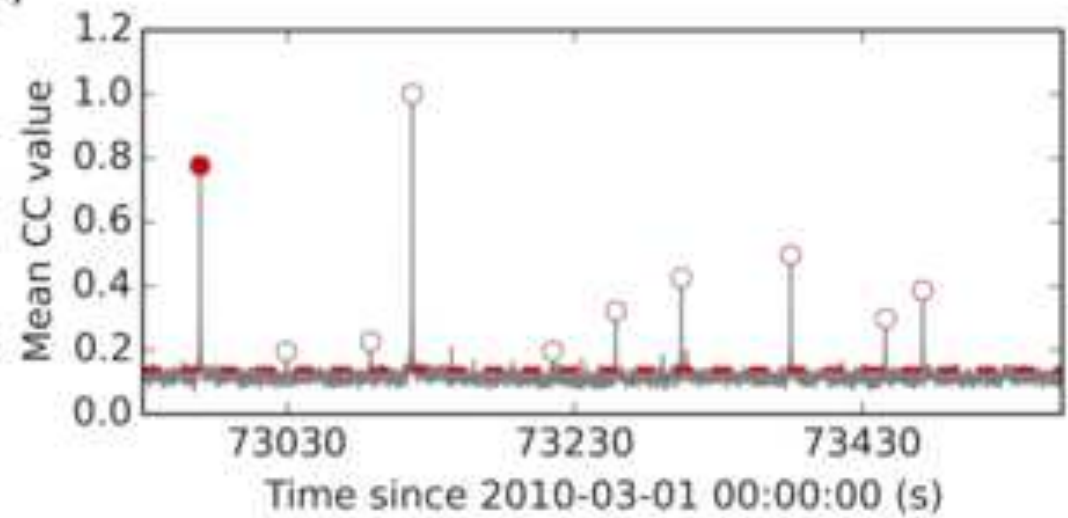

(b)

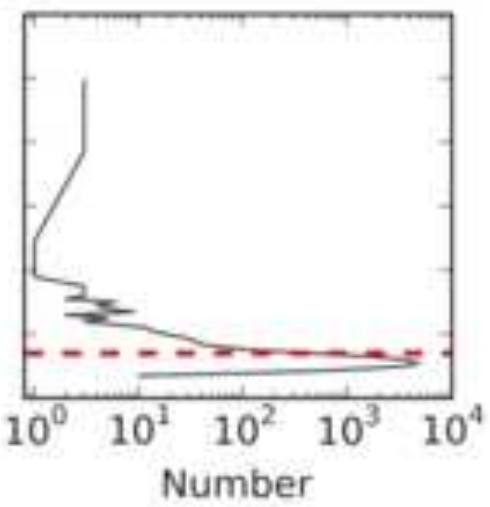

(c)

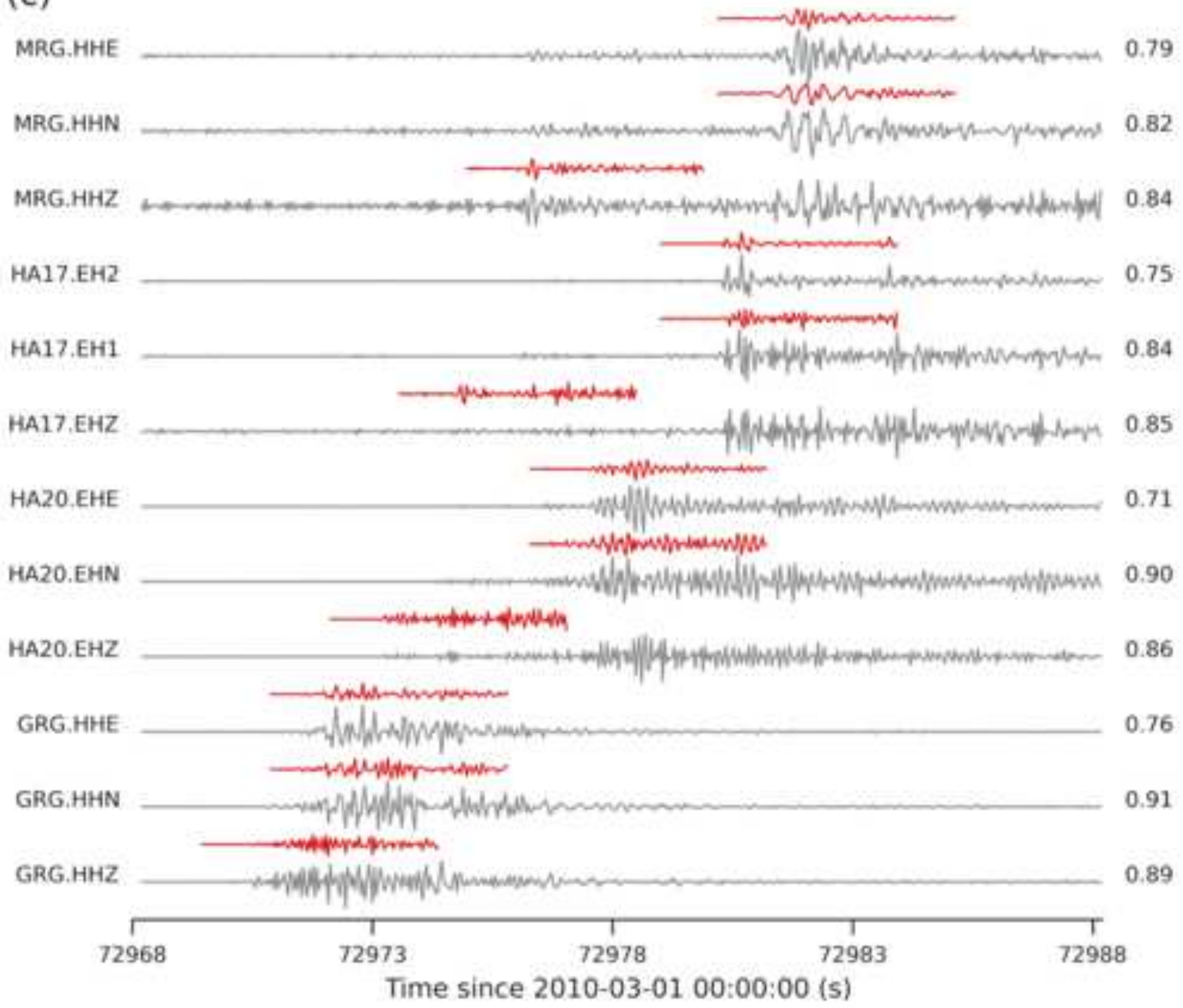


(a)
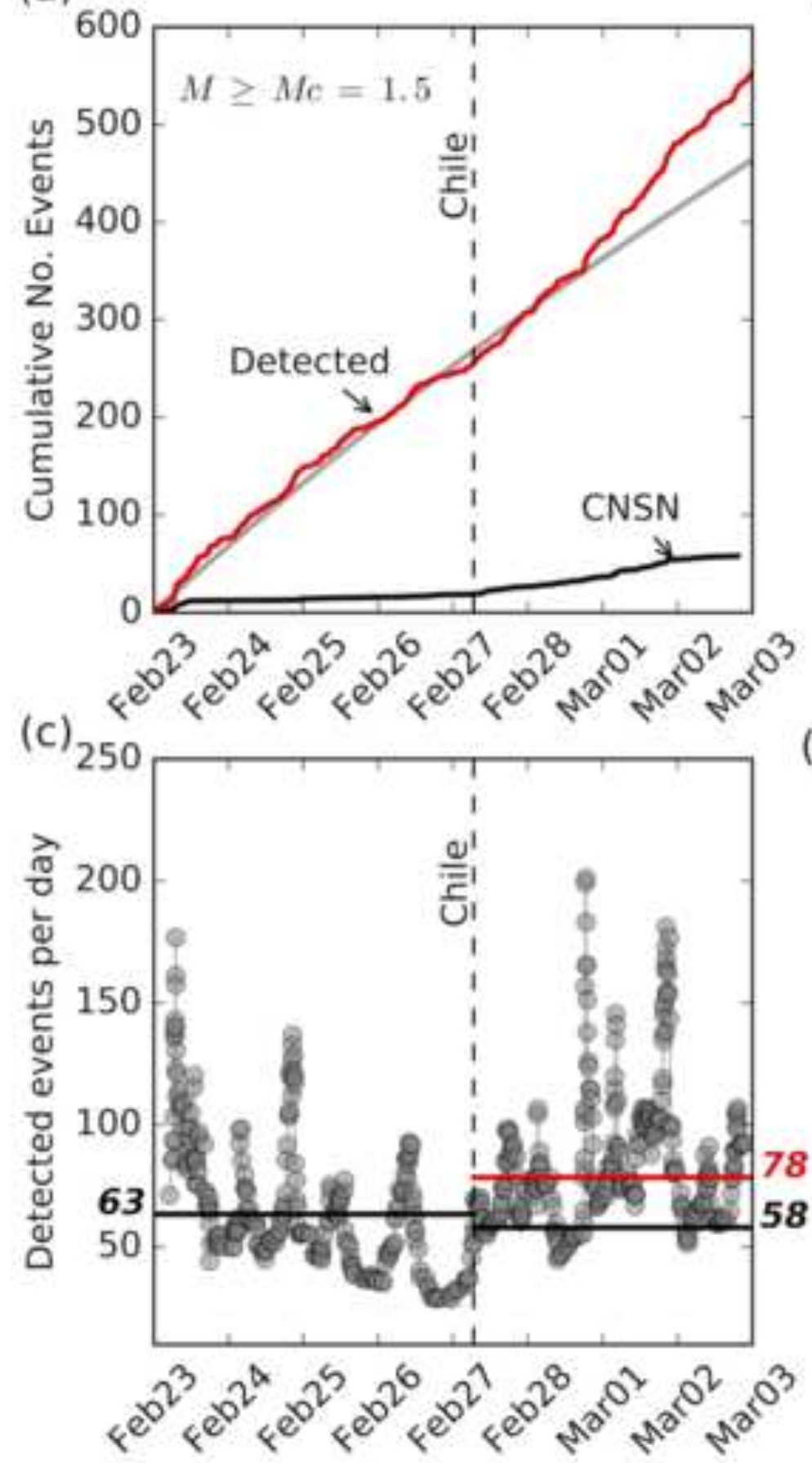

(b)

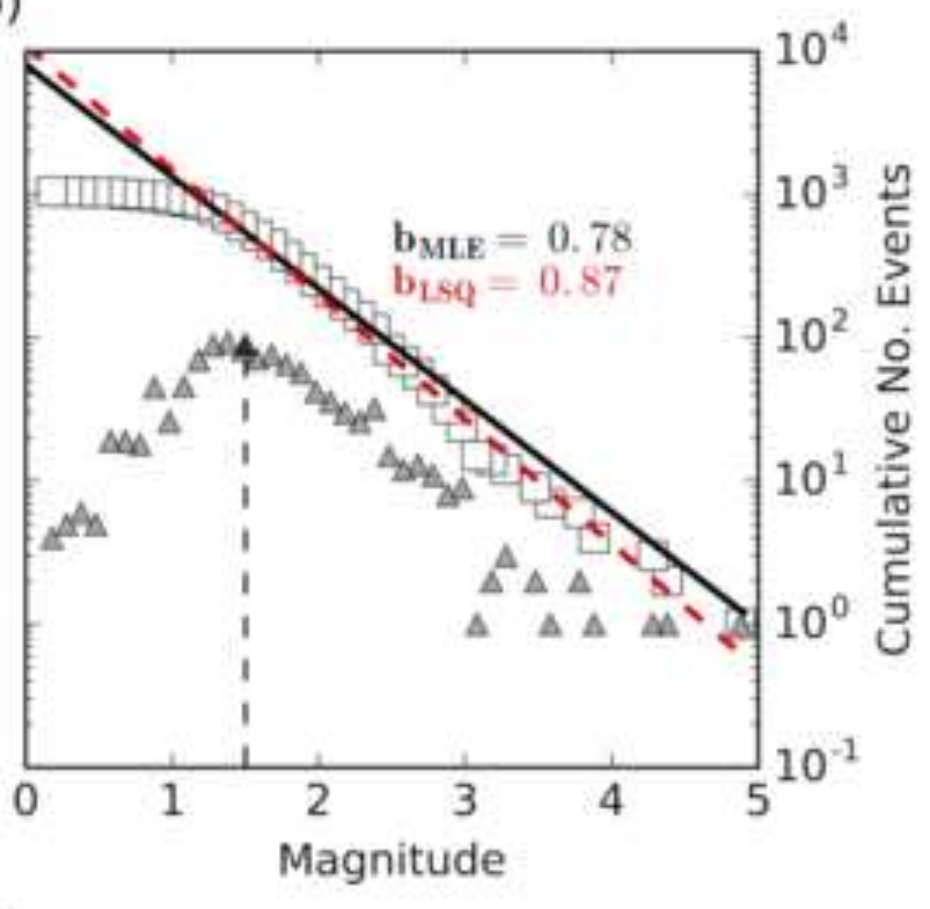

d)

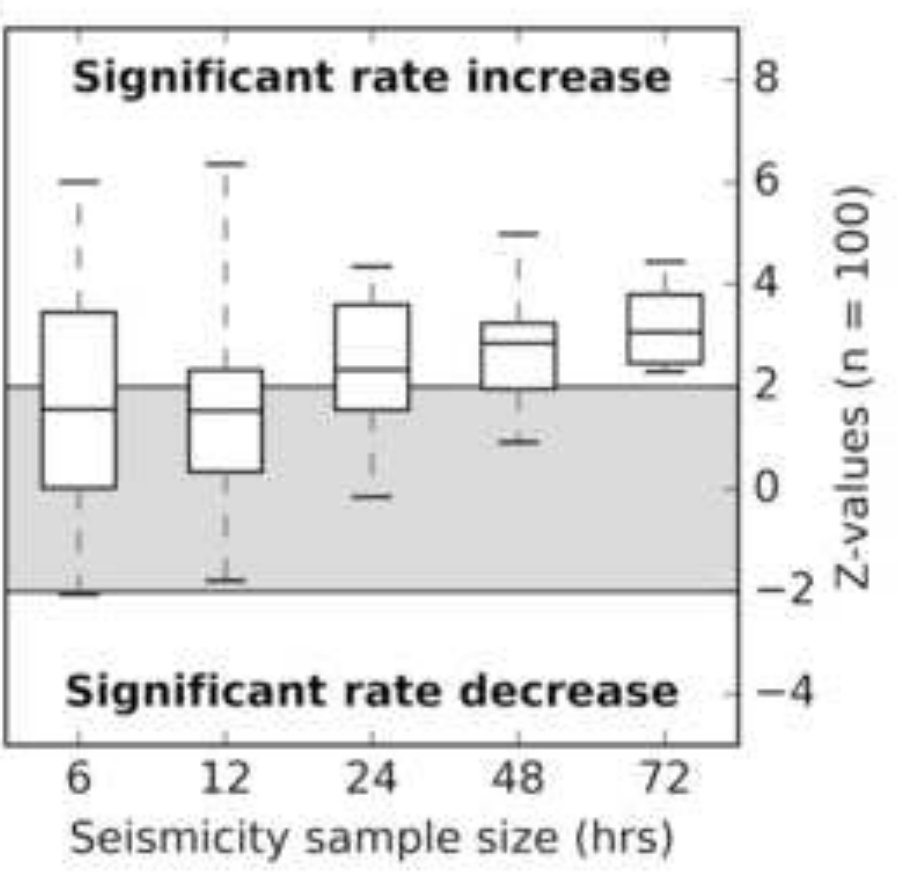

